\title{
Solar zenith angle dependence of relationships between energy inputs to the ionosphere and ion outflow fluxes
}

Naritoshi Kitamura ( $\boldsymbol{\nabla}$ kitamura@eps.s.u-tokyo.ac.jp )

The University of Tokyo https://orcid.org/0000-0002-2397-273X

Kanako Seki

The University of Tokyo

Kunihiro Keika

The University of Tokyo

Yukitoshi Nishimura

Boston University

Tomoaki Hori

Nagoya University

Masafumi Hirahara

Nagoya University

Eric J Lund

University of New Hampshire Institute for the Study of Earth Oceans and Space

Lynn M Kistler

University of New Hampshire Institute for the Study of Earth Oceans and Space

Robert J Strangeway

University of California Los Angeles

Full paper

Keywords: Auroral ion outflow, polar ionosphere, auroral precipitation, FAST satellite, cleft ion fountain, ion conics, ion beams

Posted Date: April 5th, 2021

DOI: https://doi.org/10.21203/rs.3.rs-388101/v1

License: (1) (1) This work is licensed under a Creative Commons Attribution 4.0 International License.

Read Full License 


\section{Title page:}

2 Title: Solar zenith angle dependence of relationships between energy inputs to the

3 ionosphere and ion outflow fluxes

4 Author \#1: Naritoshi Kitamura, Department of Earth and Planetary Science, Graduate

5 School of Science, The University of Tokyo, Japan, kitamura@eps.s.u-tokyo.ac.jp

6 Author \#2: Kanako Seki, Department of Earth and Planetary Science, Graduate School

7 of Science, The University of Tokyo, Japan, k.seki@eps.s.u-tokyo.ac.jp

8 Author \#3: Kunihiro Keika, Department of Earth and Planetary Science, Graduate

9 School of Science, The University of Tokyo, Japan, keika@eps.s.u-tokyo.ac.jp

10 Author \#4: Yukitoshi Nishimura, Department of Electrical and Computer Engineering

11 and Center for Space Physics, Boston University, Boston, MA, USA, toshi16@bu.edu

12 Author \#5: Tomoaki Hori, Institute for Space-Earth Environmental Research, Nagoya

13 University, Furo-cho, Chikusa-ku, Nagoya, Japan, tomo.hori@nagoya-u.jp

14 Author \#6: Masafumi Hirahara, Institute for Space-Earth Environmental Research,

15 Nagoya University, Furo-cho, Chikusa-ku, Nagoya, Japan, hirahara@nagoya-u.jp

16 Author \#7: Eric J. Lund, Institute for the Study of Earth, Oceans, and Space, Institute 
17 for the Study of Earth, Oceans, and Space, University of New Hampshire, Durham, NH,

18 USA; College Brook Scientific, Durham, NH, USA, eric.lund@unh.edu

19 Author \#8: Lynn M. Kistler, Institute for the Study of Earth, Oceans, and Space,

20 University of New Hampshire, Durham, NH, USA; Department of Physics, University

21 of New Hampshire, Durham, NH, USA, lynn.kistler@unh.edu

22 Author \#9: Robert J. Strangeway, Department of Earth, Planetary, and Space Sciences,

23 University of California in LA, Los Angeles, CA, USA, strange@igpp.ucla.edu

\section{Corresponding author: Naritoshi Kitamura}

25 


\section{Abstract}

27 The ionosphere is one of the important sources for magnetospheric plasma, particularly

28 for heavy ions with low charge states. We investigate the effect of solar illumination on

29 the number flux of ion outflow using data obtained by the Fast Auroral SnapshoT

30 satellite at 3000-4150 km altitude from 7 January 1998 to 5 February 1999 . We derive

31 empirical formulas between energy inputs and outflowing ion number fluxes for various

32 solar zenith angle ranges. We found that the outflowing ion number flux under sunlit

33 conditions increases more steeply with increasing electron density in the loss cone or

34 with increasing precipitating electron density $(>50 \mathrm{eV})$, compared with the ion flux

35 under dark conditions. Under ionospheric dark conditions, weak electron precipitation

36 can drive ion outflow with small averaged fluxes $\left(\sim 10^{7} \mathrm{~cm}^{-2} \mathrm{~s}^{-1}\right)$. The slopes of

37 relations between the DC and Alfvén Poynting fluxes and outflowing ion number fluxes

38 show no clear dependence on solar zenith angle. Intense ion outflow events $\left(>10^{8} \mathrm{~cm}^{-2}\right.$

$39 \mathrm{~s}^{-1}$ ) occur mostly under sunlit conditions (solar zenith angle $<90^{\circ}$ ). Thus, it is

40 presumably difficult to drive intense ion outflows under dark conditions, because of a

41 lack of the solar illumination (low ionospheric density and/or small scale height owing 
to low plasma temperature).

44 Keywords

45 Auroral ion outflow, polar ionosphere, auroral precipitation, FAST satellite, cleft ion

46 fountain, ion conics, ion beams

47

48 Main Text

49 1. Introduction

50 Quantifying the properties of outflowing ionospheric ions is one of the most

51 important subjects for magnetospheric studies, because the physical characteristics of

52 the magnetosphere are modulated significantly by outflowing ions. Many satellite

53 observations have demonstrated that ionospheric $\mathrm{O}^{+}$ions are supplied to the plasma

54 sheet and inner magnetosphere, especially during geomagnetically active periods (e.g.,

55 Daglis 1997; Yao et al. 2008a; Ebihara et al. 2009; Mouikis et al. 2010; Ohtani et al.

56 2011; Kronberg et al. 2012, 2015; Maggiolo and Kistler 2014; Kistler and Mouikis

57 2016; Keika et al. 2018a, 2018b; Mitani et al., 2019; Mouikis et al., 2019; Kistler et al. 
58 2019). Various modeling and observational studies have suggested that an increase in

59 the ionospheric $\mathrm{O}^{+}$ions in the magnetosphere would affect reconnection processes (e.g.,

60 Shay and Swisdak 2004; Karimabadi et al. 2011; Liu et al. 2015; Fuselier et al., 2019;

61 Tenfjord et al., 2019), location of the tail reconnection (Brambles et al. 2010; Garcia et

62 al. 2010; Wiltberger et al. 2010; Yu and Ridley 2013), growth and propagation of

63 electromagnetic ion cyclotron waves (e.g., Omidi et al. 2013; Denton et al. 2014; Nosé

64 et al., 2020), and development and decay of the ring current (e.g., Hamilton et al. 1988;

65 Keika et al. 2006; Glocer et al. 2009a, 2009b, 2013; Welling et al. 2011; Ilie et al. 2015;

66 Menz et al. 2019). Moreover, modeling studies by Brambles et al. (2011, 2013),

67 Ouellette et al. (2013), Varney et al. (2016), and Zhang et al. (2020) showed that

68 inclusion of $\mathrm{O}^{+}$ion outflows can change the mode of global magnetospheric convection:

69 from steady convection to sawtooth oscillations. Observations and effects of $\mathrm{O}^{+}$ions in

70 the magnetosphere are summarized in more detail in review papers by Keika et al.

71 (2013), Kronberg et al. (2014), Welling et al. (2016), and Yamauchi (2019).

72 Some of the $\mathrm{O}^{+}$ions are lost to the interplanetary space through the boundary layer

73 (Zong et al. 2004; Bouhram et al. 2005; Cohen et al. 2016; Zeng et al. 2020), plasma 
74 mantle (Slapak et al. 2017; Schillings et al. 2019, 2020), and/or distant tail (Seki et al.

75 1998; Kistler et al. 2010). Additionally, some $\mathrm{O}^{+}$ions are lost as energetic neutral atoms

76 due to the charge exchange process (Keika et al. 2006; Valek et al. 2018). Thus, the

77 understanding of ion outflow from the ionosphere also contributes to the understanding

78 of atmospheric loss from magnetized planets.

79 To include ion outflows from the ionosphere in global magnetospheric simulations,

80 moments of the outflowing ion distribution function can be used as the boundary

81 conditions at the inner boundary, which is typically located at $\sim 2.5$ Earth radii $\left(R_{\mathrm{E}}\right)$ in

82 geocentric distance. If temporal variations of the ion outflows are important for the

83 studies, time-dependent inner boundary conditions are necessary. There have been two

84 approaches for it: one is to use ion outflows from ionospheric simulations (e.g., Schunk and Sojka 1997; Barakat and Schunk 2006; Glocer et al. 2012, 2018, 2020; Pham et al. empirical relations between energy inputs and ion outflow fluxes (Fok et al. 2006, 2011;

88 Moore et al. 2007, 2010; Brambles et al. 2010, 2011, 2013; Damiano et al. 2010;

89 Peroomian et al. 2011; Ouellette et al. 2013). The present study provides such empirical 
relations that include effects of the solar illumination. Such empirical relations may also

91 be useful for rough validation of ion outflow simulations.

92 Using data obtained by the Fast Auroral SnapshoT (FAST) satellite, statistical studies

93 by Strangeway et al. (2005) and Brambles et al. (2011) indicated that fluxes of ion

94 outflows are correlated well with the precipitating electron density $(>50 \mathrm{eV})$, electron

95 density in the loss cone (>50 eV), and DC and Alfvén Poynting fluxes. They derived

96 empirical formulas between these energy inputs to the ionosphere and outflowing ion

97 number fluxes at $\sim 4000 \mathrm{~km}$ altitude using the data obtained near the cusp region in the

98 dayside (mostly in the postnoon sector) during a geomagnetic storm (24-26 September

99 1998, which included $\sim 30$ orbit passes). Zheng et al. (2005) also derived similar

100 empirical formulas using data obtained by the Polar spacecraft at $\sim 5000 \mathrm{~km}$ altitude (37

101 events, mostly in the dayside). Recently, Zhao et al. (2020) updated the empirical

102 formulas derived by Strangeway et al. (2005) and Brambles et al. (2011) using the mass

103 resolved ion data derived by the FAST satellite during the same geomagnetic storm as

104 previously studied by them. Hatch et al. (2020a) focused on the east-west magnetic field

105 fluctuations, and investigated the relation between the magnetic field fluctuations and 
106 ion outflows around the cusp for four geomagnetic storms in various seasons. They

107 examined the correlation of the ion outflow flux with magnetic fluctuations and showed

108 that the outflow flux has a smaller increase rate with increasing amplitude of the east-

109 west fluctuations in winter than in summer and equinox seasons.

110 The solar illumination (or season) strongly affects the ionosphere in terms of the

111 condition under which the ionosphere receives energy inputs from the magnetosphere

112 (Garner et al. 2010; Hatch et al. 2020b; Zhang et al. 2010). A statistical study by

113 Kitamura et al. (2011) that used data from the Akebono and Intercosmos satellites, and

114 the European incoherent scatter Svalbard radar reported that the temperature and scale

115 height of background thermal plasma in the topside ionosphere are strongly controlled

116 by the solar zenith angle (SZA). It causes large seasonal dependence of the electron

117 density around $2000 \mathrm{~km}$ altitude in the polar region under quiet geomagnetic conditions

118 (Kitamura et al. 2009). Using data obtained by the Defense Meteorological Satellite

119 Program, Ma et al. (2018) investigated the effect of solar illumination on ion upflows

120 and found that the effect is not simple. For example, they showed that high speed

121 upflow can occur under dark conditions, while upflows with large density can occur 
under sunlit conditions. Some statistical studies using incoherent scatter radar data have

123 identified seasonal variation of the occurrence frequency of ion upflows (Foster et al.

124 1998; Liu et al. 2001; Buchert et al. 2004; Ji et al. 2019; Ren et al. 2020), although the

125 seasonal variation seems to depend on the observed altitude and/or location of the radar.

126 The occurrence of upward ion beams is also strongly affected by the solar illumination;

127 the occurrence rate is lower under sunlit ionospheric conditions (on the basis of

128 measurements below $\sim 4000 \mathrm{~km}$ altitude) (Cattell et al. 2013), and is also lower in

129 winter, which mostly corresponds to dark conditions (on the basis of measurements

130 around $\sim 6000 \mathrm{~km}$ altitude) (Collin et al. 1998). The occurrence frequency of ion conics

131 (or transversely accelerated ions) at $\sim 1500 \mathrm{~km}$ altitude is higher in winter, which period

132 corresponds mostly to dark conditions (Klumpar 1979; Norqvist et al. 1998). Broadband

133 extremely low-frequency waves (observed below $\sim 10,000 \mathrm{~km}$ altitude (Kasahara et al.

134 2001)) and electromagnetic ion cyclotron waves (500-4000 km (Saito et al. 1987) and

$135 \sim 1500 \mathrm{~km}$ altitude (Erlandson and Zanneti 1998; Hamrin et al. 2002)), which are

136 thought to be the main driving processes of ion conics, also tend to be preferentially

137 generated under winter and/or dark conditions. These various types of observations 
support the importance of solar illumination (ionospheric conditions) for ion outflows.

139 Thus, the solar illumination may affect the empirical relationships between the energy

140 inputs and outflowing ion number fluxes. Since the SZA at the magnetic footprint of the

141 events used by Strangeway et al. (2005) and Brambles et al. (2011) was smaller than

$14292^{\circ}$, their empirical formulas represent those under sunlit ionospheric conditions.

143 Some modeling studies of ion outflows have shown a seasonal dependence (Demars

144 and Schunk 2001, 2002) or interhemispheric asymmetry (Barakat et al. 2015; Glocer et

145 al. 2020) of ion outflows, although the models are incomplete because physical

146 processes of ion outflows have not been fully understood yet.

147 To understand how strongly (sunlit or dark) ionospheric conditions affect ion

148 outflows, we derive empirical formulas of outflowing ion number fluxes as a function

149 of each energy input (electron density in the loss cone $(>50 \mathrm{eV})$, precipitating electron

150 density $(>50 \mathrm{eV}), \mathrm{DC}$ and Alfvén Poynting fluxes) for a wide SZA range $\left(45^{\circ}-145^{\circ}\right)$,

151 using data obtained by the FAST satellite (3000-4150 km altitude). The structure of this

152 manuscript goes in the following way: Section 2 describes the datasets and the event

153 selection criteria we used. Sections 3 and 4 present the results of our data analysis, 
154 followed by some discussions in Section 5.

155

\section{2. Dataset and Selection of Ion Outflow Events}

157 The FAST satellite was launched in 1996 with an initial perigee, apogee, and

158 inclination of $350 \mathrm{~km}, 4175 \mathrm{~km}$, and $83^{\circ}$, respectively. The satellite was spin-stabilized

159 with a spin period of $\sim 5 \mathrm{~s}$. The spin axis was nearly normal to the orbital plane (Carlson

160 et al. 1998). We used data obtained in four intervals between 7 January 1998 and 5

161 February 1999 (7 January 1998-4 April 1998 (North), 3 May 1998-20 July 1998

162 (South), 31 July 1998-26 October 1998 (North), and 15 December 1998-6 February

1631999 (South)). These periods are suitable for studying the impact of SZA, because the

164 orbital plane of the FAST satellite tended to be aligned to the noon-midnight meridian

165 when the apogee stayed near the pole. This orbit configuration enables the satellite to

166 traverse the auroral zone (or cusp) at various SZAs even in a single day, owing to the

167 shift of the magnetic pole from the rotational axis. In contrast, the satellite can only

168 measure very limited specific SZA repeatedly in cases where the orbital plane was

169 closely aligned to the dawn-dusk meridian. The monthly mean F10.7 index ranged 
170 between 93.4 and 150.1, which is almost the same level as the solar maximum of Solar

171 cycle 24.

172 The electron and ion spectrometers (EESA and IESA) measured two-dimensional

$173\left(360^{\circ}\right)$ electron and ion velocity distributions with an angular resolution of $11.25^{\circ}(32$

174 bins) or $5.625^{\circ}$ (64 bins in limited periods of IESA) in an energy range of $\sim 4 \mathrm{eV}-32$

$175 \mathrm{keV}$ and $\sim 3 \mathrm{eV}-24 \mathrm{keV}$, respectively (Carlson et al. 2001). During the data periods for

176 the present study, the EESA and IESA covered the energy ranges with 48 energy steps.

177 The electron density in the loss cone (see Section 4.2 for the definition) and the

178 precipitating electron density, which was proposed by Strangeway et al. (2005) and was

179 calculated using the energy flux and the number flux (see Section 4.3 for the definition),

180 include electrons in the energy range of $50 \mathrm{eV}-32 \mathrm{keV}$. This low energy limit $(50 \mathrm{eV})$ is

181 set to avoid the contamination of ionospheric photoelectrons, following Strangeway et

182 al. (2005). Background counts were subtracted from the IESA data using count rates in

183 the source cone (Appendix A1).

184 The low energy limit for calculations of field-aligned (upward positive) ion number

185 fluxes was set to $10 \mathrm{eV}$ to reduce the influence of small changes in spacecraft potential 
and the effect of spacecraft motion (ram effect) on the calculation of ion number flux. In

187 cases where the orbital velocity of FAST was not perpendicular to the magnetic field,

188 sometimes artificial fluxes owing to the ram effect became significant below $\sim 10 \mathrm{eV}$;

189 the spacecraft velocity of $\sim 6.2 \mathrm{~km} \mathrm{~s}^{-1}(\sim 3000 \mathrm{~km}$ altitude) corresponds to the energy of

$190 \sim 3.2 \mathrm{eV}$ for $\mathrm{O}^{+}$ions. Note that this lower limit $(10 \mathrm{eV})$ is higher than that used by

191 Strangeway et al. (2005) $(4 \mathrm{eV})$. This change is done to find a much larger number of

192 events quantitatively (not with visual inspection) from times when the apogee is at

193 various latitudes.

194 The magnetic field (Elphic et al. 2001) and electric field (Ergun et al. 2001) data were

195 used to derive Poynting fluxes. Poynting fluxes were calculated using electric fields

196 along the orbital velocity vector (Ealong_v) of the satellite ( $1 \mathrm{~s}$ average) and deviations

197 from the International Geomagnetic Reference Field 11th generation (IGRF-11) model

198 magnetic field (Finlay et al. 2010) perpendicular to the orbital velocity vector ( $\delta B_{\text {perp_v}}$ )

199 (1 s average). The Poynting flux of DC fields (DC Poynting flux: $<0.125 \mathrm{~Hz}$ ) was

200 calculated as the vector product of running averaged values of Ealong_v and $\delta B_{\text {perp_}} \mathrm{V}$

201 (window size: 7 data points) (Strangeway et al. 2005), and the Poynting flux of Alfvénic 
202 waves (Alfvén Poynting flux: 0.125-0.5 Hz) was the vector product of residuals of

203 Ealong_v and $\delta B_{\text {perp_v }} v$ after subtraction of the running averaged values (Brambles et al.

204 2011). For these Poynting fluxes, a positive value corresponds to a downward Poynting

205 flux. Note that the electric field perpendicular to the velocity vector of the satellite is not

206 derived owing to lack of reliable measurements of the electric field along the spin axis.

207 Thus, the magnitude of the Poynting fluxes is underestimated, and this incomplete

208 Poynting flux measurement probably contributes to somewhat large scatter in some

209 results of the present analysis on the relationship between the Poynting fluxes and the

210 ion flux (Sections 4.4 and 4.5).

211 Ion number fluxes, electron energy and number fluxes, and Poynting fluxes were

212 mapped to $1000 \mathrm{~km}$ altitude, assuming the dipole magnetic field. The particle, magnetic

213 field, and Poynting flux data were averaged over $5 \mathrm{~s}$ intervals ( $\sim 1 \mathrm{spin})$ after removing

214 erroneous data (Appendix A2), resulting in the dataset with a uniform time resolution of

$215 \quad 5 \mathrm{~s}$.

216 At magnetic footprints of the cusp, the boundary layer, and the plasma sheet, high

217 energy ions from the magnetosphere or the solar wind precipitate into the ionosphere. 
218 Since these populations contribute negatively to the ion number flux, such contribution

219 must be separated from that of the outflowing ions. In the present study, the contribution

220 of the precipitating ions was separated by referring to their energy difference: the energy

221 of outflowing ions is lower than that of the precipitating ions. Practically, the upper

222 energy limit that maximizes the field-aligned (upward positive) ion number flux (IESA)

223 was selected from about $18,30,50,100,200,350,600,1000,2000,4000$, or $10,000 \mathrm{eV}$

224 (per 3 or 4 energy bin, except for $4-10 \mathrm{keV}$ that includes 5 energy bins) in each $5 \mathrm{~s}$

225 interval. The observed flux was then integrated up to the selected upper energy limit to

226 evaluate a number flux of outflowing ions. Figure 1 shows an example of the data

227 during the main phase of a geomagnetic storm $(K p=4, A L=-500-1000 \mathrm{nT})$.

228 Electrons and high-energy (above the white line) ions from the cusp/cleft and plasma

229 sheet were detected at $\sim 19: 42$ UT and after $\sim 20: 10$ UT, respectively. A white polygonal

230 line in Figure $1 \mathrm{~b}$ is the upper energy limit selected as described above. In the region

231 where the outflowing low-energy ion number flux (Figure 1c) is large $\left(>10^{7} \mathrm{~cm}^{-2} \mathrm{~s}^{-1}\right)$,

232 the precipitating ions with high energies are appropriately separated from the

233 outflowing low-energy component. 
234 Before identification of ion outflow events, intervals of significant negative

235 spacecraft charging, which causes artificially large ion number fluxes, were identified,

236 and were treated as data gaps. Although such negative spacecraft charging was rare

237 around the apogee, even a small number of such events can affect the present statistical

238 study, because real events with very large ion number flux were also rare. A more

239 detailed explanation about the intervals is described in Appendix A3.

240 We focused on full auroral zone (or cusp) crossings as much as possible. Thus, the

241 data obtained during orbit passes that included observations of the polar cap longer than

$242200 \mathrm{~s}$ (40 data points) were used for the present statistical study. The polar cap was

243 defined with the threshold of a mean differential energy flux $\left(<10^{4.6} \mathrm{eV} \mathrm{cm}^{-2} \mathrm{~s}^{-1} \mathrm{sr}^{-1}\right.$

$\left.244 \mathrm{eV}^{-1}\right)$ of the $5 \mathrm{~s}$ averaged low-energy ion data $(110 \mathrm{eV}-24 \mathrm{keV})$. The threshold of

245 differential energy flux is identical to that used by Andersson et al. (2004). A more

246 detailed explanation about the selection of the polar cap is described in Appendix A4. A

247 green bar above the top of Figure 1 is an example of the identified polar cap periods.

248 The orbit passes at high latitudes $\left(>45^{\circ}\right.$ in invariant latitude (ILAT)) were divided into

249 an inbound and an outbound part. 
250 As the candidates of the outflow region, continuous ( $\geq 10 \mathrm{~s}, \geq 2$ data points) data

251 points with mapped ion number flux larger than $10^{7} \mathrm{~cm}^{-2} \mathrm{~s}^{-1}$ were selected. Blue bars at

252 the top of Figure 1 are an example of the candidates. To focus on ion outflows in the

253 auroral zone and cusp, candidates in the subauroral zone or lower latitude, which were

254 rare, were excluded. Details of this identification are described in Appendix A5.

255 Because the dataset (7 January 1998-5 February 1999) is very large, there are some

256 candidates of outflow regions that is not appropriate to use. Data from the inbound or

257 outbound part were not used for the statistical analysis if any of outflow regions met at

258 least one of the following criteria:

259 1. The total time length of the outflow region was $<20 \mathrm{~s} \mathrm{(4} \mathrm{data} \mathrm{points).}$

260 2. Edges of the outflow region were located $\leq 1^{\circ}$ in ILAT from the low and high

261 latitude limit of the data.

262 3. A total of data gap periods of IESA or EESA around ( $\leq 1^{\circ}$ in ILAT from the edge)

263 the outflow region exceeded $25 \%$ of the total time length of the data obtained in the

264 outflow region.

265 4. Errors of the magnetic field data occurred (Appendix A2-1). 
altitude.

270 increases exponentially with decreasing altitude (Kitamura et al. 2009, 2011), the ion

271 flux due to the ram effect increases drastically, and the ram effect creates an apparent

272 flux increase at $\sim 10 \mathrm{eV}$ at low altitudes. This criterion also helps to reduce altitude

273 dependence of the outflowing ion number fluxes above $10 \mathrm{eV}$. Although the field-

274 aligned ion number fluxes are expected to be almost continuous in the direction of

275 altitude on average at $\sim 3000 \mathrm{~km}$ altitude where the local production is negligible, ions

276 must have been energized to $>10 \mathrm{eV}$ at somewhere below the altitude of the satellite to

277 exceed the lower energy limit $(10 \mathrm{eV})$ of the present analysis. At low altitudes,

278 outflowing ions below $10 \mathrm{eV}$ may be dominant, and the outflowing ion number fluxes

279 may be significantly underestimated due to the lower energy limit, if similar data

280 obtained at very low altitudes. The limitation due to the lower energy limit of $10 \mathrm{eV}$ is

281 also discussed in Section 5. 
283 Poynting fluxes of DC fields and Alfvénic waves during all candidates of the outflow

284 region together in each inbound or outbound pass using the latitudinal width in ILAT in

285 each $5 \mathrm{~s}$ data as the weight. By using this weight for the averaging, we can treat the data

286 as if the satellite had crossed the auroral zone in the latitudinal direction with a constant

287 velocity, regardless of its orbit, which usually crosses the auroral zone obliquely. The

288 averaged data is counted as 1 event. The averaged SZA in each of these outflow events

289 is calculated using the product of the latitudinal width in ILAT and the mapped ion

290 number flux as the weight. The total number of these events was 1569. Poynting fluxes

291 were available in 1448 events out of the total 1569 events (Appendix A2-2).

\section{SZA Dependence of Ion Number Fluxes}

294 Figure 2a indicates the outflowing ion number flux (mapped to $1000 \mathrm{~km}$ altitude) for 
298 indicates that the effect of the solar illumination (likely high ionospheric density and/or

299 large scale height owing to high plasma temperature (Kitamura et al. 2011)) is important

300 for the occurrence of ion outflows with large number fluxes. This result is consistent

301 with the seasonal dependence of ion outflow discussed by Yau et al. (1985), which

302 indicates that more $\mathrm{O}^{+}$outflow occurs in summer than winter. Note that the outflowing

303 ion flux in Figure 2a cannot simply be considered as averaged fluxes for specific $K p$

304 levels, since events of small $\left(<10^{7} \mathrm{~cm}^{-2} \mathrm{~s}^{-1}\right)$ ion number fluxes could not be included in

305 the statistics.

306 Only the events near noon (0800-1600 magnetic local time (MLT)) are plotted in

307 Figure $2 \mathrm{~b}$. The events that include any data point (before averaging) outside of the

308 0800-1600 MLT range are not plotted. The figure shows that most of the events with

309 large ion number fluxes occurred near noon. In contrast, the lack of ion outflow events

310 with large number fluxes near midnight (2000-2400 or 0000-0400 MLT) (Figure 2c) is

311 consistent with the importance of solar illumination for the occurrence of ion outflows

312 with large number fluxes. Because the auroral zone around midnight is rarely

313 illuminated by the sun, presumably it is difficult to drive ion outflow with large number 
314 fluxes around midnight. As described in section 2, the orbital plane of the FAST satellite

315 tended to be aligned to the noon-midnight meridian when the apogee stayed near the

316 pole. Thus, auroral oval crossings are concentrated around noon and midnight. Because

317 the overlap (around SZA of $100^{\circ}$ ) of events around noon and midnight is limited, it is

318 difficult to investigate the difference in the empirical relation around noon and that

319 around midnight at the same SZA. Detailed analysis of the MLT effect is beyond the

320 scope of the present study.

321 Shillings et al. $(2017,2018)$ investigated $\mathrm{O}^{+}$ion outflows during large geomagnetic

322 storms using data obtained by the Cluster spacecraft as extreme cases, and reported

323 large magnitudes of $\mathrm{O}^{+}$number flux (event mean) of $3.5 \times 10^{7}-2 \times 10^{9} \mathrm{~cm}^{-2} \mathrm{~s}^{-1}$

324 (mapped to an ionospheric reference altitude with a magnetic field intensity of 50,000

$325 \mathrm{nT}$ ). The largest value of $2 \times 10^{9} \mathrm{~cm}^{-2} \mathrm{~s}^{-1}$ corresponds to $\sim 1.5 \times 10^{9} \mathrm{~cm}^{-2} \mathrm{~s}^{-1}$ at $1000 \mathrm{~km}$

326 altitude (a magnetic field intensity of $\sim 37,000 \mathrm{nT}$ (Engwall et al. 2009)). Even this flux

327 in an extreme case is within the range covered by the dataset used in the present study. 


\subsection{Empirical Formula}

332 Energy inputs (electron density in the loss cone, precipitating electron density

333 proposed by Strangeway et al. (2005), DC and Alfvén Poynting fluxes) were

334 logarithmically averaged using bins of the ion number flux (one order of magnitude was

335 divided by 10 bins). The total latitudinal widths in ILAT of the outflow events were

336 used as the weight for this averaging. The logarithmically averaged values were fitted

337 with a weighted least squares method using the following formula:

$338 F_{i}=10^{a} x^{b}$,

339 where $F_{\mathrm{i}}$ is the ion number flux (mapped to $1000 \mathrm{~km}$ altitude) in $\mathrm{cm}^{-2} \mathrm{~s}^{-1}, x$ is the

340 energy input, and $a$ and $b$ are free parameters determined by the fitting. This fitting

341 formula is the same as that used by Strangeway et al. (2005) and Brambles et al. (2011).

342 In this fitting, the sum of the total latitudinal widths in ILAT of the outflow events was

343 used as the weight. The parameters selected as the energy input are those studied by

344 Strangeway et al. (2005) and Brambles et al. (2011) and found that there are good

345 correlations with outflowing ion fluxes. The use of other energy input parameters, to 
346 find which input parameter is good, and to investigate the functional shape are beyond

347 scope of the present study.

348 As described above, we used logarithmically averaged energy inputs, not the outflow

349 events themselves, for this fitting for the following reason, because the ion number

350 fluxes used here are biased by the lower flux limit $\left(10^{7} \mathrm{~cm}^{-2} \mathrm{~s}^{-1}\right)$, which was used for

351 event identification. Thus, in cases of small energy inputs, only cases in which the ion

352 flux exceeded $10^{7} \mathrm{~cm}^{-2} \mathrm{~s}^{-1}$ were included for evaluation of the average energy input,

353 despite that there must be cases where such a small energy input can cause ion outflows

354 with the ion flux $<10^{7} \mathrm{~cm}^{-2}$ in reality. This limitation would uplift the small energy

355 input part of the regression line, and makes the gradient of the line unrealistically

356 gradual, if each of the outflow events were used for the fitting. Instead, the use of the

357 averaged energy inputs for each level of the ion number flux helps us avoid such a bias,

358 particularly for small energy input cases.

359 4.2. Empirical Relations between the Electron Density in the Loss Cone and the

$360 \quad$ Ion Number Flux

361 The electron density in the loss cone is defined as the partial electron density at the 
362 location of the satellite using 4 pitch angle bins around the precipitating direction (the

363 center of pitch angle bins ranges from $-22.5^{\circ}$ to $22.5^{\circ}$ (Northern hemisphere) or from

$364 \quad 157.5^{\circ}$ to $202.5^{\circ}$ (Southern hemisphere).

365 Figure 3 shows the relations between the electron density in the loss cone $\left(n_{\mathrm{e}} \_\mathrm{c}\right)$ in

$366 \mathrm{~cm}^{-3}(>50 \mathrm{eV})$ and the mapped ion number flux. The width of the SZA bins is $40^{\circ}$, and

367 neighboring bins overlap in half $\left(20^{\circ}\right)$ to include a larger number of events in each SZA

368 bin. The empirical formulas were derived as follows.

369 SZA $45^{\circ}-85^{\circ}: F_{i}=10^{9.162} n_{\text {e_lc }}^{3.185}$

$370 \quad \operatorname{SZA} 65^{\circ}-105^{\circ}: F_{i}=10^{9.014} n_{\mathrm{e} \_l c}^{2.686}$

371 SZA $85^{\circ}-125^{\circ}: F_{i}=10^{8.643} n_{\mathrm{e} \_l c}^{1.693}$

$372 \quad$ SZA $105^{\circ}-145^{\circ}: F_{i}=10^{8.419} n_{\mathrm{e} \_l c}^{1.100}$

373 The fitted line tends to become less steep with increasing SZA. The ion outflow

374 events with small averaged number fluxes $\left(\sim 10^{7} \mathrm{~cm}^{-2} \mathrm{~s}^{-1}\right)$ occur with smaller electron

375 densities $\left(\sim 5 \times 10^{-2} \mathrm{~cm}^{-3}\right)$ at large SZA, while ion outflow events with large number

376 fluxes $\left(>10^{8} \mathrm{~cm}^{-2} \mathrm{~s}^{-1}\right)$ occur infrequently even in cases of high electron densities $(>5 \times$

$37710^{-1} \mathrm{~cm}^{-3}$ ). Above the electron density of $\sim 4 \times 10^{-1} \mathrm{~cm}^{-3}$ (the ion number flux of $\sim 1 \times$ 
$37810^{8} \mathrm{~cm}^{-2} \mathrm{~s}^{-1}$ ), the ion outflow flux given by the empirical formulas (Equations 2-5)

379 decreases with increasing SZA at a certain magnitude of the electron density (Figure

380 3e). The exponents (b) of Equations 2 and 3 under sunlit conditions are slightly larger

381 than those derived by Strangeway et al. (2005) (their Equation $4, b=2.240$ ).

382 4.3. Empirical Relations between the Precipitating Electron Density and the Ion

383 Number Flux

384 Strangeway et al. (2005) suggested the precipitating electron density $\left(n_{\mathrm{ep}}\right)$, which has

385 the dimensions of the number density in $\mathrm{cm}^{-3}$ defined as

$386 \quad n_{\mathrm{ep}}=2.134 \times 10^{-14} f_{\mathrm{en}}^{3 / 2} / f_{\mathrm{ee}}^{1 / 2}$,

387 where $f_{\text {en }}$ is the averaged field-aligned (downward positive) electron number flux ( $>50$

$388 \mathrm{eV})$ in $\mathrm{cm}^{-2} \mathrm{~s}^{-1}$, and $f_{\text {ee }}$ is the averaged field-aligned electron energy flux $(>50 \mathrm{eV})$ in

$389 \mathrm{~mW} \mathrm{~m}^{-2}$. Note that these fluxes are mapped to $1000 \mathrm{~km}$ altitude in the present study,

390 while Strangeway et al. (2005) used local ones ( $4000 \mathrm{~km}$ altitude). Thus, the

391 precipitating electron density is $\sim 2.9$ times larger than that used by Strangeway et al.

392 (2005) under the same condition. Positive values indicate downward fluxes. This

393 precipitating electron density is presumably more useful for modeling studies than the 
394 electron density in the loss cone, since the precipitating electron density can be

395 calculated using electron fluxes mapped along field lines.

396 If the averaged energy flux and/or the averaged number flux were negative (upward),

397 the precipitating electron density became negative (11 events) or imaginary numbers

398 (40 events). Even after excluding such invalid cases, 1453 out of 1504 events (97.6\%)

399 remained available for this statistical analysis. All excluded events except one have

400 negative averaged number fluxes, which were significantly affected by upgoing low-

401 energy electron beams (Ergun et al. 1998; Elphic et al. 2000; Andersson and Ergun

402 2006) in the region of ion outflow events. Most of these events occurred at large SZA

$403\left(>100^{\circ}\right)$, which is consistent with the seasonal dependence of upward electron beams

404 (Elphic et al. 2000).

405 The SZA dependence of the relations between the precipitating electron density and

406 the ion number flux are shown in Figure 4. The result is quite similar to that between

407 the electron density in the loss cone and the ion number flux (Figure 3), although the

408 scatter of data points tends to be larger. The empirical formulas between the

409 precipitating electron density $(>50 \mathrm{eV})$ and the mapped ion number flux are derived as 
$410 \quad$ listed below.

$411 \quad$ SZA $45^{\circ}-85^{\circ}: F_{i}=10^{8.069} n_{\mathrm{ep}}^{2.984}$

$412 \quad$ SZA $65^{\circ}-105^{\circ}: F_{i}=10^{8.259} n_{\mathrm{ep}}^{2.208}$

$413 \quad \mathrm{SZA} 85^{\circ}-125^{\circ}: F_{i}=10^{8.391} n_{\mathrm{ep}}^{1.578}$

$414 \quad$ SZA $105^{\circ}-145^{\circ}: F_{i}=10^{8.484} n_{\mathrm{ep}}^{1.185}$

415 Below the precipitating electron density of $\sim 1.5 \mathrm{~cm}^{-3}$ (the ion number flux of $\sim 6 \times$

$41610^{8} \mathrm{~cm}^{-2} \mathrm{~s}^{-1}$ ), the ion outflow flux given by the empirical formulas (Equations 7-10)

417 increases with increasing SZA at a certain magnitude of the precipitating electron

418 density (Figure 4e). The ion number flux given by these formulas tends to be slightly

419 smaller than that derived by Strangeway et al. (2005) (their Equation 3 after the

420 altitudinal correction) under sunlit conditions.

421

\subsection{Empirical Relations between the DC Poynting Flux and the Ion Number}

422 Flux

423 We excluded cases in which the averaged DC Poynting flux was negative (upward),

424 and 1389 out of 1448 events $(95.9 \%)$ remained available for this statistical analysis.

425 Most of the excluded events (46 out of 59) occurred at large SZA $\left(>95^{\circ}\right)$. 
426 The relation between the DC Poynting flux and the ion number flux does not show

427 clear SZA dependence, as seen from Figure 5. The fitted functions are similar, but the

428 large Poynting flux events tend to occur more under sunlit conditions than under dark

429 conditions. Most of the averaged values of the DC Poynting flux in each flux bin at

430 various SZA ranges are within the error bars (standard deviations) in the flux range

431 where a significant number of events are present even at large SZAs. The empirical

432 formulas between $S_{\mathrm{DC}}$ (mapped DC Poynting flux in $\mathrm{mW} \mathrm{m}^{-2}$ ) and the mapped ion

433 number flux are derived as listed below.

$434 \quad \mathrm{SZA} 45^{\circ}-85^{\circ}: F_{i}=10^{6.792} S_{\mathrm{DC}}^{1.757}$

$435 \quad$ SZA $65^{\circ}-105^{\circ}: F_{i}=10^{7.162} S_{\mathrm{DC}}^{1.423}$

$436 \quad \mathrm{SZA} 85^{\circ}-125^{\circ}: F_{i}=10^{7.398} S_{\mathrm{DC}}^{1.323}$

437 SZA $105^{\circ}-145^{\circ}: F_{i}=10^{7.298} S_{\mathrm{DC}}^{1.822}$

438 Since the exponents did not show any systematic SZA dependence, we also

439 calculated a regression line using all the events without classification of SZA.

SZA $45^{\circ}-145^{\circ}: F_{i}=10^{7.218} S_{\mathrm{DC}}^{1.499}$

441 The ion number fluxes from these formulas are roughly comparable to that from the 
443 altitudinal correction) (Figure 5f).

444 4.5. Empirical Relations between the Alfvén Poynting Flux and the Ion Number

$445 \quad$ Flux

446 After the exclusion of cases in which the averaged Alfvén Poynting flux was negative

447 (upward), 1267 out of 1448 events (87.5\%) remained available for this statistical

448 analysis. Excluded events were not strongly concentrated to large SZAs (104 out of 181

449 at large SZAs $\left(>95^{\circ}\right)$ ) as compared with that in the cases of the DC Poynting flux.

450 Similar to the relations between the DC Poynting flux and the ion number flux

451 (Figure 5 and Equations 11-14), the relation between the Alfvén Poynting flux and the

452 ion number flux does not show clear SZA dependence in the flux range where a large

453 number of events are present, as seen from Figure 6. The empirical formulas between

$454 S_{\mathrm{A}}$ (mapped Alfvén Poynting flux in $\mathrm{mW} \mathrm{m}^{-2}$ ) and the mapped ion number flux are

455 derived as listed below.

$\mathrm{SZA} 45^{\circ}-85^{\circ}: F_{i}=10^{10.780} S_{A}^{1.432}$ 
$458 \quad$ SZA $85^{\circ}-125^{\circ}: F_{i}=10^{10.418} S_{A}^{1.360}$

$459 \quad$ SZA $105^{\circ}-145^{\circ}: F_{i}=10^{10.026} S_{A}^{1.178}$

460 We also calculated a regression line using all the events without classification of SZA.

$461 \quad \mathrm{SZA} 45^{\circ}-145^{\circ}: F_{i}=10^{11.062} S_{A}^{1.656}$

462 The ion number fluxes from these formulas are roughly comparable to that from the

463 empirical formula derived by Brambles et al. (2011) (after the altitudinal correction))

464 (Figure 6f).

465

466 5. Discussion

467 The new empirical formulas derived in the present study include information about

468 the SZA effect. This new information is valuable for investigating day-night and/or

469 interhemispheric asymmetries (around solstice) of ion outflows in global

470 magnetospheric models. Since the solar activity level (monthly mean $F_{10.7}$ index) from

471 January 1998 to February 1999 was almost the same as the latest solar maximum (Solar

472 cycle 24), the empirical formulas obtained in the present study should be applicable to

473 comparisons of the ion composition in the magnetosphere between the global models 
and measurements by the Van Allen Probes and the Magnetospheric Multiscale

475 missions. Effects of solar activity will be studied in the future.

476 It is still impossible to determine the dominant energy input for the outflowing ion

477 flux among the four on the basis of empirical formulas. One may think that the Poynting

478 fluxes have a strong contribution, because the empirical formulas between the Poynting

479 fluxes and ion number fluxes do not strongly depend on SZA. The error bars, which

480 often spreads about an order of magnitude of the Poynting fluxes at a certain ion

481 number flux (Figures 3 and 4), however, tend to be larger than those of electron

482 precipitation, which is usually within a factor of $\sim 3-5$ (Figures 5 and 6).

483 Since the low-energy ions have limited upward velocities (order of $10 \mathrm{~km} \mathrm{~s}^{-1}$ ), it

484 takes at least several minutes for them to reach the altitude of $4000 \mathrm{~km}$ from the

485 ionosphere. Thus, the energy inputs to the ionosphere at least several minutes before the

486 satellite observations may be most relevant to the observed ion number fluxes at $\sim 4000$

$487 \mathrm{~km}$ altitude. Observations by the Cluster spacecraft indicate that the $\mathrm{O}^{+}$ion number flux

488 fluctuates on the timescale of several minutes (Bouhram et al. 2004; Nilsson et al.

489 2008). This would imply that energy inputs that drive outflows also have fluctuations 
490 with similar timescales. Such fluctuations may explain the large error bars in Figures $3-$

491 6. Nevertheless, the present results are based on a substantial number of events and we

492 believe that the empirical relations can provide the average profile of ion outflow for

493 varying energy inputs, which is readily usable for global magnetospheric simulations.

494 Even if the energy input is constant after a certain onset time, the outflowing $\mathrm{O}^{+}$ion

495 number flux increases dramatically in the initial $\sim 10 \mathrm{~min}$ after the driving forces turned

496 on in the models (Su et al. 1999; Horwitz and Zeng 2009). Whereas this time scale

497 would change if different settings of the driving force are used, the duration of energy

498 inputs would also contribute to the large deviation. If the intensity and duration of

499 energy inputs are enough to modify and control the conditions of background plasma,

500 SZA dependence would almost disappear (Horwitz and Zeng, 2009). That is, however,

501 not the case for at least some events, because the empirical relation of the electron

502 density in the loss cone or precipitating electron density and the outflowing ion number

503 flux shows SZA dependence.

504 A combination of a latitudinally narrow cusp (Meng 1982, 1983; Kitamura et al.

505 2010a) and fast ionospheric convection during the main phase of geomagnetic storms 
causes ion energization with a short duration in a certain flux tube. In such cases, the

507 duration of energization and the time-lag discussed above would be especially important

508 (Varney et al. 2015) in addition to the energy input and SZA. The derived empirical

509 relations would also be averaged characteristics from the perspective of a limited

510 duration of ion energization.

511 Note that only ions above $10 \mathrm{eV}$ are included in the present study. Since transverse

512 energization of ions also occurs above $\sim 4000 \mathrm{~km}$ altitude (Peterson et al. 1992; Miyake

513 et al. 1993), the ion number flux above $10 \mathrm{eV}$ for higher altitudes (for example, the

514 inner boundary of magnetospheric simulations) is probably underestimated. During

515 geomagnetic storms, $\mathrm{O}^{+}$ion outflows with energies below $\sim 10 \mathrm{eV}$ with very large fluxes

$516\left(>10^{9} \mathrm{~cm}^{-2} \mathrm{~s}^{-1}\right.$ mapped to $1000 \mathrm{~km}$ altitude) are present poleward of the cusp (observed

517 at $\sim 9000 \mathrm{~km}$ altitude) (Kitamura et al. 2010b). Such a population was not included in

518 the present analysis owing to the difficulty in use of ion data below $10 \mathrm{eV}$, although how

519 often such component becomes significant still remains as an open question, due to the

520 lack of detailed ion observations below $\sim 10 \mathrm{eV}$. This will become an important subject

521 of observations in future missions. 
523 outflow fluxes have been used as the boundary conditions of $\mathrm{O}^{+}$ions at the inner

524 boundary in global magnetospheric simulations (Fok et al. 2006, 2011; Moore et al.

525 2007, 2010; Brambles et al. 2010, 2011, 2013; Damiano et al. 2010; Peroomian et al.

526 2011; Ouellette et al. 2013). However, it is not clear whether $\mathrm{O}^{+}$ions are dominant in

527 many cases, because there are many observations of ion outflows with $\mathrm{H}^{+}$ion fluxes

528 larger than $\mathrm{O}^{+}$ion fluxes (Tung et al. 2001; Peterson et al. 2001, 2006; Andersson et al.

529 2004; Wilson et al. 2004; Maes et al. 2015). The polar wind is present as thermal energy

530 ion outflows (e.g., Yau et al. 2007 and references therein). Observational studies by

531 Kitamura et al. (2016) showed that upward velocity of $\mathrm{O}^{+}$ions are almost zero at least

532 up to $\sim 7000 \mathrm{~km}$ altitude in the sunlit polar cap region under geomagnetically quiet

533 condition (the region and condition where very small auroral energy input are

534 expected), while $\mathrm{H}^{+}$ions have upward velocity at least above $\sim 3000 \mathrm{~km}$ altitude. This

535 fact clearly indicates that $\mathrm{H}^{+}$ion outflows (polar wind type) do not need strong energy

536 input, in contrast to $\mathrm{O}^{+}$ion outflows. As for such $\mathrm{H}^{+}$ions, different types of recent

537 satellite observations (direct thermal energy ion measurements and estimations of 
components masked by spacecraft potential (Huddleston et al. 2005), measurements of

539 spacecraft potential and wake (Engwall et al. 2009; André et al. 2015), and estimations

540 using photoelectron outflows (Kitamura et al. 2012, 2015)) indicate that the number

541 flux of the polar wind is $\sim 2 \times 10^{8} \mathrm{~cm}^{-2} \mathrm{~s}^{-1}$ (mapped to $1000 \mathrm{~km}$ altitude). This flux is

542 larger than that for most of the events (especially for geomagnetically quiet periods)

543 shown in Figure 2. This polar wind type outflow is expected to exist also at the auroral

544 zone. Thus, if background (polar wind) $\mathrm{H}^{+}$ions can be accelerated up to $10 \mathrm{eV}$,

545 additional $\mathrm{O}^{+}$ions may not be necessary for driving ion outflows with small fluxes

$546\left(<10^{8} \mathrm{~cm}^{-2} \mathrm{~s}^{-1}\right)$. Analyses that use mass resolved data (for example, the data from the

547 Time-of-flight Energy, Angle, Mass Spectrograph (TEAMS) instrument on the FAST

548 satellite (Klumpar et al. 2001), which are under re-calibration (Zhao et al. 2020)) will be

549 important in the future, probably especially for ion outflow events with small fluxes.

550

551

\section{Summary and Conclusions}

552 To understand how strongly ionospheric conditions (sunlit or dark) affect ion

553 outflows, we derived empirical formulas between energy inputs (electron density in the 
554 loss cone $(>50 \mathrm{eV})$, precipitating electron density $(>50 \mathrm{eV})$, mapped DC and Alfvén

555 Poynting fluxes) and outflowing ion number fluxes (mapped to $1000 \mathrm{~km}$ altitude) for a

556 wide range of SZA $\left(45^{\circ}-145^{\circ}\right)$, using data obtained by the FAST satellite (3000-4150

557 km altitude) from 7 January 1998 to 5 February 1999 (monthly mean $F_{10.7}$ index of

$558 \quad 93.4-150.1)$

559 Ion outflow events with large averaged fluxes $\left(>10^{8} \mathrm{~cm}^{-2} \mathrm{~s}^{-1}\right)$ occur mostly under

560 sunlit ionospheric conditions $\left(\mathrm{SZA}<90^{\circ}\right)$. Thus, the effect of the solar illumination

561 (presumably high ionospheric density and/or large scale height owing to high plasma

562 temperature) probably plays an important role in the occurrence of ion outflows with

563 large averaged fluxes.

564 Empirical relations between the electron density in the loss cone $(>50 \mathrm{eV})$ or

565 precipitating electron density $(>50 \mathrm{eV})$ and the outflowing ion number fluxes show

566 clear dependence on SZA at the ionospheric footprint. The outflowing ion number flux

567 increases with increasing electron density in the loss cone and precipitating electron

568 density, and the gradient of empirical formulas becomes less steep with increasing SZA.

569 SZA dependence was not seen in the empirical relations between the Poynting fluxes 
570 (DC and Alfvén) and the outflowing ion number flux. Note that the electric fields

571 perpendicular to the velocity vector of the satellite are not derived owing to the lack of

572 reliable measurements of the electric fields along the spin axis. Thus, the magnitude of

573 the Poynting fluxes is probably underestimated, and this incomplete Poynting flux

574 measurement probably contributes to somewhat large scatter of the data points in the

575 present analyses on the relationship between the Poynting fluxes and the ion flux.

576 Ionospheric conditions (sunlit or dark) affect ion outflows. Under dark ionospheric

577 conditions, although weak electron precipitation can drive ion outflows with small

578 averaged fluxes $\left(\sim 10^{7} \mathrm{~cm}^{-2} \mathrm{~s}^{-1}\right)$, it is hard to drive intense ion outflows $\left(>10^{8} \mathrm{~cm}^{-2} \mathrm{~s}^{-1}\right)$

579 presumably owing to low ionospheric $\mathrm{O}^{+}$ion densities and/or a small scale height of $\mathrm{O}^{+}$

580 ions.

581

582 Appendix

583 A1. Calculation and Subtraction of Background of IESA

584 Background counts of IESA were subtracted from IESA data using count rates in the

585 source cone. Although the method of background subtraction was basically similar to 
587 count rate, since the background count rates of IESA were slightly different from that of

588 EESA. Another difference from the method of background subtraction by Yao et al.

589 (2008a, 2008b) is that the background count rate was calculated by a linear least-

590 squares fitting using a moving window ( $25 \mathrm{~s}$ ) for better handling of the data with

591 various time resolutions, while they used boxcar averaged ones. This calculation was

592 performed after the removals of spikes, which were presumably caused by erroneous

593 data.

594

595 A2. Rejection of Erroneous Data

596 A2.1. Magnetic Field Data

597 In some cases, processed magnetic field data are apparently incorrect. To remove

598 such incorrect data quantitatively as much as possible, the outflow events that satisfied

599 the following two criteria at any of the $5 \mathrm{~s}$ averaged data points in the outflow regions

600 were excluded from the present statistical analyses.

601 1. The magnetic field intensity that was calculated from observed data differs from 
602

that from the IGRF model by $>10 \%$.

603 2. The direction of the magnetic field differs from that calculated using the IGRF

604 model by $>5^{\circ}$.

605 Additionally, two events were excluded by visual inspection of the magnetic field

606 data.

607 A2.2. Electric Field Data

608 Sometimes an unusually large electric field was recorded just after a data gap. Thus,

609 if there was any gap in the electric field data, the $5 \mathrm{~s}$ averaged Poynting flux at the

610 period was not used. If Poynting fluxes were not available at any of data points in the

611 outflow regions, the event was excluded from the statistical analyses in Sections 4.4 and

6124.5.

613 A2.3. Ion and Electron Data

614 Sometimes ion or electron data are apparently incorrect. The ion data were excluded

615 if counts at all pitch angle bins of IESA in one third (top, middle, or bottom) of the

616 energy bins were zero. This is the most typical type of the error. The counts do not

617 become zero at such a large number of bins in the correct data (Figures 1a and 1b). 
618 Frequently, another type of error occurs just after the change of the observational

619 modes: Slow survey ( $\sim 2.5 \mathrm{~s}$ resolution) and Fast survey $(\sim 0.625$ or $\sim 0.3125 \mathrm{~s}$

620 resolution). Seven (two) data points were excluded after the change to Fast (Slow)

621 survey mode. This number was determined by visual inspection. The same rejection

622 processes were also applied to electron data.

623

\section{A3. Periods of Significant Negative Spacecraft Charging}

625 If the spacecraft is charged negatively, thermal energy ions are attracted from all

626 directions. A $5 \mathrm{~s}$ period (one averaged data point) was regarded as a period of significant

627 spacecraft charging, if there was at least one energy bin $(4-70 \mathrm{eV})$ that the differential

628 energy fluxes exceeded $5 \times 10^{6} \mathrm{eV}^{-1} \mathrm{~cm}^{-2} \mathrm{~s}^{-1} \mathrm{sr}^{-1} \mathrm{eV}^{-1}$ in all of the four pitch angle

629 ranges: $-16.875^{\circ}-16.875^{\circ}, 40^{\circ}-140^{\circ}, 163.125^{\circ}-196.875^{\circ}$, and $220^{\circ}-320^{\circ}$. The adjacent

6305 s periods are also excluded for safety: some of data before averaging may be affected

631 by the charging. By visual inspections of all outflow events, this definition is enough to

632 exclude intervals of significant spacecraft charging with large ion number fluxes that

633 can strongly affect the identification of outflow events. The upper energy limit of $70 \mathrm{eV}$ 
634 is to avoid misidentification in the cusp in cases where ion precipitation was so intense

635 that the differential energy flux exceeded $5 \times 10^{6} \mathrm{eV}^{-1} \mathrm{~cm}^{-2} \mathrm{~s}^{-1} \mathrm{sr}^{-1} \mathrm{eV}^{-1}$ even in the

636 source cone owing to pitch angle scattering.

637

638 A4. Identification of the Polar Cap

639 The polar cap was defined with the use of $5 \mathrm{~s}$ averaged low-energy ion data $(110 \mathrm{eV}-$

$64024 \mathrm{keV})$, according to the threshold of a mean differential energy flux $\left(<10^{4.6} \mathrm{eV}^{-1} \mathrm{~cm}^{-2}\right.$

$641 \mathrm{~s}^{-1} \mathrm{sr}^{-1} \mathrm{eV}^{-1}$ ) described by Andersson et al. (2004). The mean differential energy flux

642 was calculated by using pitch angle ranges of $-30^{\circ}-30^{\circ}, 150^{\circ}-210^{\circ}$, and $40^{\circ}-140^{\circ}$ or

$643220^{\circ}-320^{\circ}$. In some orbits, contamination caused by solar radiation increases count

644 rates around $90^{\circ}$ or $270^{\circ}$ at high latitudes. Because this increase affects the

645 identification of the polar cap, the mean differential energy flux in the pitch angle range

646 of $40^{\circ}-140^{\circ}$ or $220^{\circ}-320^{\circ}$, whichever smaller, is selected to avoid this contamination

647 (Kitamura et al. 2015). Continuous ( $\geq 10 \mathrm{~s}, \geq 2$ data points) periods in which the mean

648 differential energy flux met the criterion were selected as candidates of the polar cap.

649 Sometimes this criterion was satisfied for data obtained in the subauroral zone. To 
650 exclude such cases, the candidates that are connected to the region where energetic ions

651 ( $>4 \mathrm{keV}$ ) show double loss cones (Appendix A5) without a data gap of $\geq 60 \mathrm{~s}$ or

652 equatorward of such regions were excluded. In some cases, short candidates that were

653 appeared between the auroral zone and the region of the double loss cone could not be

654 excluded. There were some cases in which the region of double loss cone was not

655 identified and candidates in the subauroral zone could not be excluded. All these two

656 types of cases, however, had polar cap periods much longer than $200 \mathrm{~s}$, and thus the

657 overlooking did not affect the exclusion of the outflow events.

658 Although contamination owing to solar radiation causes increase in count rates, the

659 increase occurs around the pitch angle of $90^{\circ}$ at high latitudes. Thus, this does not

660 strongly affect the calculations of field-aligned ion fluxes in the outflow regions $\left(>10^{7}\right.$

$661 \mathrm{~cm}^{-2} \mathrm{~s}^{-1}$ ). This is one of the reasons why we set the lower flux limit to identify the

662 outflow regions. In some cases, the contamination causes the apparent field-aligned ion

663 fluxes of the order of $10^{6} \mathrm{~cm}^{-2} \mathrm{~s}^{-1}$ (mapped to $1000 \mathrm{~km}$ altitude). To treat ion outflows

664 with fluxes smaller than $\sim 10^{7} \mathrm{~cm}^{-2} \mathrm{~s}^{-1}$ in the future, this apparent flux must be

665 corrected. 
666

667 A5. Identification of Double Loss Cones and the Subauroral Zone

668 Identification of regions of double loss cones was performed if the mean differential

669 energy flux of ions above $4 \mathrm{keV}$ in the pitch angle ranges of $40^{\circ}-140^{\circ}$ and $220^{\circ}-320^{\circ}$

670 (trapped population) were larger than $10^{4.6} \mathrm{eV}^{-1} \mathrm{~cm}^{-2} \mathrm{~s}^{-1} \mathrm{sr}^{-1} \mathrm{eV}^{-1}$. The periods of

671 double loss cones were defined as cases where the mean differential energy flux above 4

$672 \mathrm{keV}$ near the center of the loss cone (in the pitch angle range from $163.125^{\circ}$ to $196.875^{\circ}$

673 (Northern Hemisphere) or from $-16.875^{\circ}$ to $16.875^{\circ}$ (Southern Hemisphere)) was lower

674 than $50 \%$ of those in the pitch angle ranges of $40^{\circ}-140^{\circ}$ and $220^{\circ}-320^{\circ}$. Examples are

675 shown above Figure 1 with red bars. Even if there were data gaps in the interval of

676 double loss cones, the interval was treated as one continuous interval ( 1940 UT). To

677 avoid misidentifications, short intervals ( 1 or 2 data points with double loss cones) were

678 excluded.

679 Very energetic ion conics that extended above $4 \mathrm{keV}$ could be misidentified as a

680 region of double loss cones, although such cases were very rare at this altitude. Thus, in

681 the case in which the ion number flux above $4 \mathrm{keV}$ exceeded $10^{6} \mathrm{~cm}^{-2} \mathrm{~s}^{-1}$ (mapped to 
$6821000 \mathrm{~km}$ altitude), the region was treated as the region of double loss cones only if both

683 sides of the case satisfied the criteria of double loss cones.

684 The region of ILAT $<45^{\circ}$ or high background count rates ( $>50$ counts $/ \mathrm{s}$ ) that were

685 connected to ILAT $<65.9^{\circ}(L<6)$ were removed (marked as subauroral zone). In this

686 removal, even if there were data gaps in the interval of high background count rates, the

687 interval was regarded as connected. To focus on outflows in the auroral zone, the

688 poleward boundary of the most equatorward region of double loss cones in the

689 remaining part of the inbound or outbound pass was selected as the equatorward

690 boundary of the region for the analyses (poleward of the subauroral zone). Examples of

691 the identified subauroral zones are shown above Figure 1 with black bars.

692

693 Declarations

$694 \quad$ Ethics approval and consent to participate

695

Not applicable

696

\section{Consent for publication}

697

Not applicable 

angle. 
714

715

716

717

718

719

720

721

722

723

724

725

726

727

728

729

\section{Competing interests}

The authors declare that they have no competing interests.

\section{Funding}

NK was supported by a Research Fellowship of the Japan Society for the

Promotion of Science (JSPS), JSPS KAKENHI Grant Number 24·5283.

NK was supported by Grant-In-Aid for Young Scientist 19K14781 from

JSPS and MEXT of Japan. KS was supported by Grant-In-Aid for

Scientific Research (B) 24340118 from JSPS and MEXT of Japan. KK is

supported by the GEMSIS project at STEL/Nagoya University. Part of

the work of KK and TH was done at the ERG-Science Center operated

by ISAS/JAXA and ISEE/Nagoya University. The work of YN was

supported by NASA grant 80NSSC18K0657, 80NSSC20K0604 and

80NSSC20K0725, NSF grant AGS-1907698, and AFOSR grant FA9559-

16-1-0364. EJL and LMK were supported by NASA grant

80NSSC19K0073.

\section{Authors' contributions}



attended scientific discussion and approved the final manuscript.

\section{Acknowledgements}

734 We acknowledge J. P. McFadden and C. W. Carlson for use of the EESA and IESA data of FAST (http://sprg.ssl.berkeley.edu/data/fast/11/).

736

737

\section{$738 \quad$ References}

739 Andersson L, Ergun RE (2006) Acceleration of antiearthward electron fluxes in the

740 auroral region. J Geophys Res 111:A07203. https://doi.org/10.1029/2005JA011261

741 Andersson L, Peterson WK, McBryde KM (2004) Dynamic coordinates for auroral ion 742 outflow. J Geophys Res 109:A08201. https://doi.org/10.1029/2004JA010424

743 André M., Li K, Eriksson AI (2015) Outflow of low-energy ions and the solar cycle. J

744 Geophys Res Space Phys 120:1072-1085. https://doi.org/10.1002/2014JA020714

745 Barakat AR, Schunk RW (2006) A three-dimensional model of the generalized polar wind. 
747 Barakat AR, Eccles JV, Schunk RW (2015) Effects of geographic-geomagnetic pole offset 748 on ionospheric outflow: Can the ionosphere wag the magnetospheric tail? Geophys 749 Res Lett 42:8288-8293. https://doi.org/10.1002/2015GL065736

750 Bouhram M, Klecker B, Miyake W, Rème H, Sauvaud J-A, Malingre M, Kistler L, Blăgău A (2004) On the altitude dependence of transversely heated $\mathrm{O}^{+}$distributions in the cusp/cleft. Ann Geophys 22(5):1787-1798. https://doi.org/10.5194/angeo-22-17872004

754 Bouhram M, Klecker B, Paschmann G, Haaland S, Hasegawa H, Blagau A, Rème H, 755 Sauvaud JA, Kistler LM, Balogh A (2005) Survey of energetic $\mathrm{O}^{+}$ions near the 756 dayside mid-latitude magnetopause with cluster. Ann Geophys 23(4):1281-1294. https://doi.org/10.5194/angeo-23-1281-2005

758 Brambles OJ, Lotko W, Daminao PA, Zhang B, Wiltberger M, Lyon J (2010) Effects of causally driven cusp $\mathrm{O}^{+}$outflow on the stormtime magnetosphere-ionosphere system using a multi-fluid global simulation. J Geophys Res 115:A00J04. 
762 Brambles OJ, Lotko W, Zhang B, Wiltberger M, Lyon J, Strangeway RJ (2011)

763 Magnetosphere sawtooth oscillations induced by ionospheric outflow. Science,

$764 \quad 332: 1183-1186$. https://doi.org/10.1126/science.1202869

765 Brambles OJ, Lotko W, Zhang B, Ouellette J, Lyon J, Wiltberger M (2013) The effects of

766 ionospheric outflow on ICME and SIR driven sawtooth events. J Geophys Res Space

767 Phys 118, 6026-6041. https://doi.org/10.1002/jgra.50522

768 Buchert SC, Ogawa Y, Fujii R, van Eyken AP (2004) Observations of diverging field-

769

aligned ion flow with the ESR. Ann Geophys 22(3):889-899.

$770 \quad$ https://doi.org/10.5194/angeo-22-889-2004

771 Cattell C, Dombeck J, Eskolin M, Hanson L, Lorshbough DE, Carlson CW, McFadden J,

772 Temerin M (2013) FAST observations of solar illumination and solar cycle

773 dependence of the acceleration of upflowing ion beams on auroral field lines. $\mathrm{J}$

774 Geophys Res Space Phys, 118:3203-3213. https://doi.org/10.1002/jgra.50302

775 Carlson CW, Pfaff RF, Watzin JG (1998) The Fast Auroral SnapshoT (FAST) Mission.

776 Geophys Res Lett 25:2013-2016. https://doi.org/10.1029/98GL01592

777 Carlson, CW, McFadden JP, Turin P, Curtis DW, Magoncelli A (2001) The electron and 

ion plasma experiment for FAST. Space Sci Rev 98:33-65. https://doi.org/10.1023/A:1013139910140

Cohen IJ, Mauk BH, Anderson BJ, Westlake JH, Sibeck DG, Giles BL, Pollock CJ, Turner DL, Fennell JF, Blake JB, Clemmons JH, Jaynes AN, Baker DN, Craft JV, Spence HE, Niehof JT, Reeves GD, Torbert RB, Russell CT, Strangeway RJ, Magnes W, Trattner KJ, Fuselier SA, Burch JL (2016) Observations of energetic particle escape at the magnetopause: Early results from the MMS Energetic Ion Spectrometer (EIS). Geophys Res Lett 43, 5960-5968. https://doi.org/10.1002/2016GL068689

786 Collin HL, Peterson WK, Lennartsson OW, Drake JF (1998) The seasonal variation of 787 auroral ion beams. Geophys Res Lett 25:4071-4074. https://doi.org/10.1029/1998GL900090

789

Daglis IA (1997) The role of magnetosphere-ionosphere coupling in magnetic storm

790 dynamics. In: Tsurutani BT, Gonzalez WD, Kamide Y, Arballo JK (ed) Magnetic

791 Storms. Geophysical Monograph Series, vol 98, AGU, Washington, D. C., pp 107-

793 Damiano PA, Brambles OJ, Lotko W, Zhang B, Wiltberger M, Lyon J (2010) Effects of 
796 Demars HG, Schunk RW (2001) Seasonal and solar cycle variations of the polar wind. J

797 Geophys Res 106:8157-8168. https://doi.org/10.1029/2000JA000386

798 Demars HG, Schunk RW (2002) Three-dimensional velocity structure of the polar wind.

799 J Geophys Res 107(A9):1250. https://doi.org/10.1029/2001JA000252

800 Denton RE, Jordanova VK, Fraser BJ (2014) Effect of spatial density variation and $\mathrm{O}^{+}$

801 concentration on the growth and evolution of electromagnetic ion cyclotron waves. J

802 Geophys Res Space Phys 119:8372-8395. https://doi.org/10.1002/2014JA020384

803 Ebihara Y, Kasahara S, Seki K, Miyoshi Y, Fritz TA, Chen J, Grande M, Zurbuchen TH

804 (2009) Simultaneous entry of oxygen ions originating from the Sun and Earth into the

805 inner magnetosphere during magnetic storms. J Geophys Res 114:A05219.

806 https://doi.org/10.1029/2009JA014120

807 Elphic RC, Bonnell J, Strangeway RJ, Carlson CW, Temerin M, McFadden JP, Ergun RE,

808 Peria W (2000) FAST observations of upward accelerated electron beams and 809 downward field-aligned currentregion. In Ohtani SI, Fujii R, Hesse M, Lysak RL (eds) 
810 Magnetospheric Current Systems. Geophysical Monograph Series, vol. 118, AGU,

811 Washington, D. C., pp 173-180.

812 Elphic RC, Means JD, Snare RC, Strangeway RJ, Kepko L, Ergun RE (2001) Magnetic

813 field instruments for the Fast Auroral Snapshot Explorer. Space Sci Rev 98:151-168.

814 https://doi.org/10.1007/978-94-010-0332-2_6

815 Engwall E, Eriksson AI, Cully CM, André M, Puhl-Quinn PA, Vaith H, Torbert R (2009)

816 Survey of cold ionospheric outflows in the magnetotail. Ann Geophys 27(8):3185-

817 3201. https://doi.org/10.5194/angeo-27-3185-2009

818 Ergun RE, Carlson CW, McFadden JP, Mozer FS, Delory GT, Peria W, Chaston CC,

819 Temerin M, Roth I, Muschietti L, Elphic R, Strangeway R, Pfaff R, Cattell CA,

820 Klumpar D, Shelley E, Peterson W, Moebius E, Kistler L (1998) FAST satellite

821 observations of large-amplitude solitary structures. Geophys Res Lett 25:2041-2044.

822 https://doi.org/10.1029/98GL00636

823 Ergun RE, Carlson CW, Mozer FS, Delory GT, Temerin M, McFadden JP, Pankow D,

824 Abiad R, Harvey P, Wilkes R, Primbsch H, Elphic R, Strangeway R, Phaff R, Cattell

825 CA (2001) The FAST satellite fields instrument. Space Sci Rev 98:67-91. 
827 Erlandson RE, Zanetti LJ (1998) A statistical study of auroral electromagnetic ion cyclotron waves. J Geophys Res 103:4627-4636. https://doi.org/10.1029/97JA03169

829 Finlay CC, Maus S, Beggan CD, Bondar TN, Chambodut A, Chernova TA, Chulliat A, 830 Golovkov VP, Hamilton B, Hamoudi M, Holme R, Hulot G, Kuang W, Langlais B, International, 183:1216-1230. https://doi.org/10.1111/j.1365-246X.2010.04804.x

836 Fok MC, Moore TE, Brandt PC, Delcourt DC, Slinker SP, Fedder JA (2006) Impulsive enhancements of oxygen ions during substorms. J Geophys Res 111:A10222. https://doi.org/10.1029/2006JA011839 
842 Foster C, Lester N, Davies JA (1998) A statistical study of diurnal, seasonal and solar

843 cycle variations of F-region and topside auroral upflows observed by EISCAT 844 between 1984 and 1996. Ann Geophys 16(10):1144-1158. $845 \quad$ https://doi.org/10.1007/s00585-998-1144-0

846 Fuselier SA, Mukherjee J, Denton MH, Petrinec SM, Trattner KJ, Toledo-Redondo S, 847 André M, Aunai N, Chappell CR, Glocer A, Haaland S, Hesse M, Kistler LM, 848 Lavraud B, Li WY, Moore TE, Graham D, Tenfjord P, Dargent J, Vines SK, 849 Strangeway RJ, Burch JL (2019) High-density $\mathrm{O}^{+}$in Earth's outer magnetosphere and 850 its effect on dayside magnetopause magnetic reconnection. J Geophys Res Space Phys 851 124:10257-10269. https://doi.org/10.1029/2019JA027396

852 Garcia KS, Merkin VG, Hughes WJ (2010) Effects of nightside $\mathrm{O}^{+}$outflow on 853 magnetospheric dynamics: results of multifluid MHD modeling. J Geophys Res 115:A00J09. https://doi.org/10.1029/2010JA015730

855 Garner TW, Taylor BT, Gaussiran II TL, Coley WR, Hairston MR, Rich FJ (2010)

856 Statistical behavior of the topside electron density as determined from DMSP 857 observations: A probabilistic climatology. J Geophys Res 115:A07306. 
859 Glocer A, Tóth G, Gombosi T, Welling D. (2009a) Modeling ionospheric outflows and

860 their impact on the magnetosphere, initial results. J Geophys Res 114:A05216.

861 https://doi.org/10.1029/2009JA014053

862 Glocer A, Tóth G, Ma Y, Gombosi T, Zhang JC, Kistler LM (2009b) Multifluid BlockAdaptive-Tree Solar wind Roe-type Upwind Scheme: Magnetospheric composition and dynamics during geomagnetic storms-Initial results. J Geophys Res 114:A12203. https://doi.org/10.1029/2009JA014418

866 Glocer A, Kitamura N, Toth G, Gombosi T (2012) Modeling solar zenith angle effects on the polar wind. J Geophys Res 117:A04318. https://doi.org/10.1029/2011JA017136

868 Glocer A, Fok M, Meng X, Toth G, Buzulukova N, Chen S, Lin K (2013) CRCM + 869 BATS-R-US two-way coupling. J Geophys Res Space Phys 118:1635-1650.

871 Glocer A, Toth G, Fok MC (2018) Including kinetic ion effects in the coupled global 872 ionospheric outflow solution. J Geophys Res Space Phys 123:2851-2871. 873 https://doi.org/10.1002/2018JA025241 
874 Glocer A, Welling D, Chappell CR, Toth G, Fok MC, Komar C, Kang SB, Buzulukova

875 N, Ferradas C, Bingham S, Mouikis C (2020) A case study on the origin of near-Earth

876 plasma. J Geophys Res Space Phys 125:e2020JA028205.

877 https://doi.org/10.1029/2020JA028205

878 Hamilton DC, Gloeckler G, Ipavich FM, Stüdemann W, Wilken B, Kremser G (1988)

879 Ring current development during the great geomagnetic storm of February 1986. J

880 Geophys Res 93:14343-14355. https://doi.org/10.1029/JA093iA12p14343

881 Hamrin M, Norqvist P, André M, Eriksson AI (2002) A statistical study of wave properties

882 and electron density at $1700 \mathrm{~km}$ in the auroral region. J Geophys Res 107(A8):1204.

883 https://doi.org/10.1029/2001JA900144

884 Hatch SM, Moretto T, Lynch KA, Laundal KM, Gjerloev JW, Lund EJ (2020a) The

885 relationship between cusp region ion outflows and east-west magnetic field

886 fluctuations at 4,000-km altitude. J Geophys Res Space Phys 125:e2019JA027454.

887 https://doi.org/10.1029/2019JA027454

888 Hatch SM, Haaland S, Laundal KM, Moretto T, Yau A, Bjoland LM, Reistad JP, Ohma

889 A, Oksavik K (2020b) Seasonal and hemispheric asymmetries of F region polar cap 
890 plasma density: Swarm and CHAMP observations. J Geophys Res Space Phys

891 125:e2020JA028084. https://doi.org/10.1029/2020JA028084

892 Horwitz JL, Zeng W (2009) Physics-based formula representations of high-latitude

893 ionospheric outflows: $\mathrm{H}^{+}$and $\mathrm{O}^{+}$densities, flow velocities and temperature vs. soft

894 electron precipitation, wave-driven transverse heating, and solar zenith angle effects.

$895 \quad$ J Geophys Res 114:A01308. https://doi.org/10.1029/2008JA013595

896 Huddleston MM, Chappell CR, Delcourt DC, Moore TE, Giles BL, Chandler MO (2005)

897 An examination of the process and magnitude of ionospheric plasma supply to the

898 magnetosphere. J Geophys Res 110:A12202. https://doi.org/10.1029/2004JA010401

899 Ilie R, Liemohn MW, Toth G, Ganushkina NY, Daldorff LKS (2015) Assessing the role

900 of oxygen on ring current formation and evolution through numerical experiments. J

901 Geophys Res Space Phys 120:4656-4668. https://doi.org/10.1002/2015JA021157

902 Ji EY, Jee G, Lee C (2019) Characteristics of the occurrence of ion upflow in association

903 with ion/electron heating in the polar ionosphere. J Geophys Res Space Phys

904 124:6226-6236. https://doi.org/10.1029/2019JA026799

905 Karimabadi H, Roytershteyn V, Mouikis CG, Kistler LM, Daughton W (2011) Flushing 
906 effect in reconnection: Effects of minority species of oxygen ions. Planet Space Sci

907 59:526-536. https://doi.org/10.1016/j.pss.2010.07.014

908 Kasahara Y, Hosoda T, Mukai T, Watanabe S, Kimura I, Kojima H, Niitsu R (2001)

909 ELF/VLF waves correlated with transversely accelerated ions in the auroral region

910 observed by Akebono. J Geophys Res 106:21123-21136.

911 https://doi.org/10.1029/2000JA000318

912 Keika K, Nose M, Brandt P, Ohtani S, Mitchell DG, Roelof EC (2006) Contribution of

913 charge exchange loss to the storm time ring current decay: IMAGE/HENA

914 observations. J Geophys Res 111:A11S12. https://doi.org/10.1029/2006JA011789

915 Keika K, Kistler LM, Brandt PC (2013) Energization of $\mathrm{O}^{+}$ions in the Earth's inner

916 magnetosphere and the effects on ring current buildup: A review of previous

917 observations and possible mechanisms. J Geophys Res Space Phys 118:4441-4464.

918 https://doi.org/10.1002/jgra.50371

919 Keika K, Seki K, Nosé M, Miyoshi Y, Lanzerotti LJ, Mitchell DG, Gkioulidou M,

920 Manweiler JW (2018a) Three-step buildup of the 17 March 2015 storm ring current:

921 Implication for the cause of the unexpected storm intensification. J Geophys Res 
923 Keika K, Kasahara S, Yokota S, Hoshino M, Seki K, Nosé M, Amano T, Miyoshi Y, 924 Shinohara I (2018b) Ion energies dominating energy density in the inner 925 magnetosphere: Spatial distributions and composition, observed by Arase/MEP-i.

927 Kistler LM, Mouikis CG (2016) The inner magnetosphere ion composition and local time https://doi.org/10.1002/2015JA021883

930 Kistler LM, Galvin AB, Popecki MA, Simunac KDC, Farrugia C, Moebius E, Lee MA, Sauvaud JA, Thompson B, Russell CT (2010) Escape of $\mathrm{O}^{+}$through the distant tail plasma sheet. Geophys Res Lett 37:L21101. https://doi.org/10.1029/2010GL045075

934 Kistler LM, Mouikis CG, Asamura K, Yokota S, Kasahara S, Miyoshi Y, Keika K, 935 Matsuoka A, Shinohara I, Hori T, Kitamura N, Petrinec SM, Cohen IJ, Delcourt DC 936 (2019) Cusp and nightside auroral sources of $\mathrm{O}^{+}$in the plasma sheet. J Geophys Res 937 Space Phys 124:10036-10047. https://doi.org/10.1029/2019JA027061 
938 Kitamura N, Shinbori A, Nishimura Y, Ono T, Iizima M, Kumamoto A (2009) Seasonal

939 variations of the electron density distribution in the polar region during

940 geomagnetically quiet periods near solar maximum. J Geophys Res 114:A01206.

941 https://doi.org/10.1029/2008JA013288

942 Kitamura N, Nishimura Y, Ono T, Kumamoto A, Shinbori A, Iizima M, Matsuoka A,

943 Hairston MR (2010a) Temporal variations and spatial extent of the electron density

944 enhancements in the polar magnetosphere during geomagnetic storms. J Geophys Res

945 115:A00J02. https://doi.org/10.1029/2009JA014499

946 Kitamura N, Nishimura Y, Ono T, Ebihara Y, Terada N, Shinbori A, Kumamoto A, Abe T,

947 Yamada M, Watanabe S, Matsuoka A, Yau AW (2010b) Observations of very-low-

948 energy $(<10 \mathrm{eV})$ ion outflows dominated by $\mathrm{O}^{+}$ions in the region of enhanced electron

949 density in the polar cap magnetosphere during geomagnetic storms. J Geophys Res

950

115:A00J06. https://doi.org/10.1029/2010JA015601

951 Kitamura N, Ogawa Y, Nishimura Y, Terada N, Ono T, Shinbori A, Kumamoto A, Truhlik

952 V, Smilauer J (2011) Solar zenith angle dependence of plasma density and

953 temperature in the polar cap ionosphere and low-altitude magnetosphere during 
954 geomagnetically quiet periods at solar maximum. J Geophys Res 116:A08227.

955 https://doi.org/10.1029/2011JA016631

956 Kitamura N, Seki K, Nishimura Y, Terada N, Ono T, Hori T, Strangeway RJ (2012)

957 Photoelectron flows in the polar wind during geomagnetically quiet periods. J

$958 \quad$ Geophys Res 117:A07214. https://doi.org/10.1029/2011JA017459

959 Kitamura N, Seki K, Nishimura Y, McFadden JP (2015) Limited impact of escaping 960 photoelectrons on the terrestrial polar wind flux in the polar cap. Geophys Res Lett 961 42, 3106-3113. https://doi.org/10.1002/2015GL063452

962 Kitamura N, Seki K, Nishimura Y, Abe T, Yamada M, Watanabe S, Kumamoto A, 963 Shinbori A, Yau AW (2016) Thermal and Low-energy Ion Outflows in and through 964 the Polar Cap. In Chappell CR, Schunk RW, Banks PM, Burch JL, Thorne RM (eds) 965 Magnetosphere-Ionosphere Coupling in the Solar System. Geophysical Monograph 966 Series, vol 222, AGU, Washington, D. C., pp 91-100. 967 https://doi.org/10.1002/9781119066880.ch7

968 Klumpar DM (1979) Transversely accelerated ions: an ionospheric source of hot 969 magnetospheric ions. J Geophys Res 84:4229-4237. 
971 Klumpar DM, Möbius E, Kistler LM, Popecki M, Hertzberg E, Crocker K, Granoff M, 972 Tang L, Carlson CW, McFadden J, Klecker B, Eberl F, Künneth E, Kästle H, Ertl M, 973 Peterson WK, Shelly EG, Hovestadt D (2001) The time-of-flight energy, angle, mass 974 spectrograph (TEAMS) experiment for FAST. Space Sci Rev 98:197-219. $975 \quad$ https://doi.org/10.1007/978-94-010-0332-2_8

976 Kronberg EA, Haaland SE, Daly PW, Grigorenko EE, Kistler LM, Fränz M, Dandouras 977 I (2012) Oxygen and hydrogen ion abundance in the near-Earth magnetosphere: Statistical results on the response to the geomagnetic and solar wind activity conditions. J Geophys Res 117:A12208. https://doi.org/10.1029/2012JA018071

980

Kronberg EA, Ashour-Abdalla M, Dandouras I, Delcourt DC, Grigorenko EE, Kistler LM, 981 Kuzichev IV, Liao J, Maggiolo R, Malova HV, Orlova KG, Peroomian V, Shklyar DR, 982 Shprits YY, Welling DT, Zelenyi LM (2014) Circulation of heavy ions and their 983 dynamical effects in the magnetosphere: recent observations and models. Space Sci Rev 184:173-235. https://doi.org/10.1007/s11214-014-0104-0 
Dandouras I (2015) Distribution of energetic oxygen and hydrogen in the near-Earth plasma sheet. J Geophys Res Space Phys 120:3415-3431. https://doi.org/10.1002/2014JA020882

Liu H, Ma SY, Schlegel K (2001) Diurnal, seasonal, and geomagnetic variations of large field-aligned ion upflows in the high-latitude ionospheric F region. J Geophys Res 106:24651-24661. https://doi.org/10.1029/2001JA900047

992 Liu YH, Mouikis CG, Kistler LM, Wang S, Roytershteyn V, Karimabadi H (2015) The 993 heavy ion diffusion region in magnetic reconnection in the Earth's magnetotail. J 994 Geophys Res Space Phys 120:3535-3551. https://doi.org/10.1002/2015JA020982

995 Ma YZ, Zhang QH, Xing ZY, Jayachandran PT, Moen J, Heelis RA, Wang Y (2018) 996 Combined contribution of solar illumination, solar activity, and convection to ion 997 upflow above the polar cap. J Geophys Res Space Phys 123:4317-4328. https://doi.org/10.1029/2017JA024974

999 Maes L, Maggiolo R, De Keyser J, Dandouras I, Fear RC, Fontaine D, Haaland S (2015)

1000 Solar illumination control of ionospheric outflow above polar cap arcs. Geophys Res 
1002 Maggiolo R, Kistler LM (2014) Spatial variation in the plasma sheet composition:

1003 dependence on geomagnetic and solar activity. J Geophys Res Space Phys 119:2836-

1004 2857. https://doi.org/10.1002/2013J A019517

1005 Meng CI (1982) Latitudinal variation of the polar cusp during a geomagnetic storm.

1006 Geophys Res Lett 9:60-63. https://doi.org/10.1029/GL009i001p00060

1007 Meng CI (1983) Case studies of the storm time variation of the polar cusp. J Geophys

$1008 \quad$ Res 88:137-149. https://doi.org/10.1029/JA088iA01p00137

1009 Menz AM, Kistler LM, Mouikis CG, Spence HE, Henderson MG (2019) Effects of a

1010 realistic $\mathrm{O}^{+}$source on modeling the ring current. J Geophys Res Space Phys,

1011 124:9953-9962. https://doi.org/10.1029/2019JA026859

1012 Mitani K, Seki K, Keika K, Gkioulidou M, Lanzerotti LJ, Mitchell DG, Kletzing CA,

1013 Yoshikawa A, Obana Y (2019) Statistical study of selective oxygen increase in high-

1014 energy ring current ions during magnetic storms. J Geophys Res Space Phys

$1015 \quad$ 124:3193-3209. https://doi.org/10.1029/2018JA026168

1016 Miyake W, Mukai T, Kaya N (1993) On the evolution of ion conics along the field line

1017 from EXOS D observations. J Geophys Res 98:11127-11134. 
1019 Moore TE, Fok MC, Delcourt DC, Slinker SP, Fedder JA (2007) Global aspects of solar 1020 wind-ionosphere interactions. J Atmos Solar Terr Phys 69:265-278. 1021 https://doi.org/10.1016/j.jastp.2006.08.009

1022 Moore TE, Fok MC, Delcourt DC, Slinker SP, Fedder JA (2010) Global response to local 1023 ionospheric mass ejection. J Geophys Res 115:A00J14. 1024 https://doi.org/10.1029/2010JA015640

1025 Mouikis CG, Kistler LM, Liu YH, Klecker B, Korth A, Dandouras I (2010) $\mathrm{H}^{+}$and $\mathrm{O}^{+}$ 1026 content of the plasma sheet at 15-19 Re as a function of geomagnetic and solar activity.

1027 J Geophys Res 115:A00J16. https://doi.org/10.1029/2010JA015978

1028 Mouikis CG, Bingham ST, Kistler LM, Farrugia CJ, Spence HE, Reeves GD, Gkioulidou

1029 M, Mitchell DG, Kletzing CA (2019) The storm-time ring current response to ICMEs

1030 and CIRs using Van Allen Probe Observations. J Geophys Res Space Phys 124:9017-

1031 9039. https://doi.org/10.1029/2019JA026695

1032 Nilsson H, Waara M, Marghitu O, Yamauchi M, Lundin R, Rème H, Sauvaud JA, 1033 Dandouras I, Lucek E, Kistler LM, Klecker B, Carlson CW, Bavassano-Cattaneo MB, 
1034 Korth A (2008) Transients in oxygen outflow above the polar cap as observed by the

1035 Cluster spacecraft. Ann Geophys 26:3365-3373. https://doi.org/10.5194/angeo-26-

$1036 \quad 3365-2008$

1037 Nosé M, Matsuoka A, Kumamoto A., et al. (2020) Oxygen torus and its coincidence with

1038 EMIC wave in the deep inner magnetosphere: Van Allen Probe B and Arase

1039 observations. Earth Planets Space 72:111. https://doi.org/10.1186/s40623-020-

$1040 \quad 01235-\mathrm{w}$

1041 Norqvist P, André M, Tyrland M (1998) A statistical study of ion energization

1042 mechanisms in the auroral region. J Geophys Res 103:23459-23473.

$1043 \quad$ https://doi.org/10.1029/98JA02076

1044 Ohtani S, Nosé M, Christon SP, Lui ATY (2011) Energetic $\mathrm{O}^{+}$and $\mathrm{H}^{+}$ions in the plasma

1045 sheet: Implications for the transport of ionospheric ions. J Geophys Res 116:A10211.

$1046 \quad$ https://doi.org/10.1029/2011JA016532

1047 Omidi N, Bortnik J, Thorne R, Chen L (2013) Impact of cold $\mathrm{O}^{+}$ions on the generation

1048 and evolution of EMIC waves. J Geophys Res Space Phys 118:434-445.

1049 https://doi.org/10.1029/2012JA018319 
1050 Ouellette JE, Brambles OJ, Lyon JG, Lotko W, Rogers BN (2013) Properties of outflow-

1051 driven sawtooth substorms. J Geophys Res Space Phys 118:3223-3232.

1052 https://doi.org/10.1002/jgra.50309

1053 Peterson WK, Collin HL, Doherty MF, Bjorklund CM (1992) $\mathrm{O}^{+}$and $\mathrm{He}^{+}$restricted and

1054 extended (BI-modal) ion conic distributions. Geophys Res Lett 19:1439-1442.

1055 https://doi.org/10.1029/92GL01613

1056 Peterson WK, Collin HL, Yau AW, Lennartsson OW (2001) Polar/Toroidal Imaging

1057 Mass-Angle Spectrograph observations of suprathermal ion outflow during solar

1058 minimum conditions. J Geophys Res 106:6059-6066.

1059 https://doi.org/10.1029/2000JA003006

1060 Peroomian V, El-Alaoui M, Brandt PC (2011) The ion population of the magnetotail

1061 during the 17 April 2002 magnetic storm: Large-scale kinetic simulations and

1062

IMAGE/HENA observations. J Geophys Res 116:A05214.

1063 https://doi.org/10.1029/2010JA016253

1064 Peterson WK, Collin HL, Lennartsson OW, Yau AW (2006) Quiet time solar illumination

1065 effects on the fluxes and characteristic energies of ionospheric outflow. J Geophys 
1067 Pham KH, Lotko W, Varney RH, Zhang B, \& Liu J (2021) Thermospheric impact on the magnetosphere through ionospheric outflow. Journal of Geophys Res Space Phys 126:e2020JA028656. https://doi.org/10.1029/2020JA028656

Ren J, Zou S, Lu J, Giertych N, Chen Y, Varney RH, Reimer AS (2020) Statistical study of ion upflow and downflow observed by PFISR. J Geophys Res Space Phys 125:e2020JA028179. https://doi.org/10.1029/2020JA028179

1073 Saito H, Yoshino T, Sato N (1987) Narrow-banded ELF emissions over the southern polar region. Planet Space Sci 35:745-752. https://doi.org/10.1016/0032-0633(87)90034-1 (1998) Statistical properties and possible supply mechanisms of tailward cold $\mathrm{O}^{+}$ beams in the lobe/mantle regions. J Geophys Res 103:4477-4489. https://doi.org/10.1029/97JA02137

1079 Schunk RW, Sojka JJ (1997) Global ionosphere-polar wind system during changing 1080 magnetic activity. Geophys Res 102:11,625-11,651. 
1082 Schillings A, Nilsson H, Slapak R, Yamauchi M, Westerberg L-G (2017) Relative 1083 outflow enhancements during major geomagnetic storms-Cluster observations. Ann 1084 Geophys 35(6):1341-1352. https://doi.org/10.5194/angeo-35-1341-2017

1085 Schillings A, Nilsson H, Slapak R, Wintoft P, Yamauchi M, Wik M, Dandouras I, Carr $1086 \mathrm{CM}$ (2018) $\mathrm{O}^{+}$escape during the extreme space weather event of 4-10 September 1087 2017. Space Weather 16(9):1363-1376. https://doi.org/10.1029/2018SW001881

1088 Schillings A, Slapak R, Nilsson H, Yamauchi M, Dandouras I, Westerberg LG (2019)

1089 Earth atmospheric loss through the plasma mantle and its dependence on solar wind 1090 parameters. Earth Planets Space 71:70. https://doi.org/10.1186/s40623-019-1048-0.

1091 Schillings A, Gunell H, Nilsson H, De Spiegeleer A, Ebihara Y, Westerberg LG, 1092 Yamauchi M, Slapak R (2020) The fate of $\mathrm{O}^{+}$ions observed in the plasma mantle: 1093 particle tracing modelling and cluster observations. Ann Geophys 38:645-656. 1094 https://doi.org/10.5194/angeo-38-645-2020

1095 Slapak R, Schillings A, Nilsson H, Yamauchi M, Westerberg L-G, Dandouras I (2017) 1096 Atmospheric loss from the dayside open polar region and its dependence on 1097 geomagnetic activity: implications for atmospheric escape on evolutionary timescales. 
1099 Shay MA, Swisdak M (2004) Three-species collisionless reconnection: Effect of $\mathrm{O}^{+}$on ionospheric outflows as observed at intermediate altitudes. J Geophys Res 110:A03221. https://doi.org/10.1029/2004JA010829

Su YJ, Caton RG, Horwitz JL, Richards PG (1999) Systematic modeling of soft-electron precipitation effects on high-latitude $F$ region and top side ionospheric upflows. J Geophys Res 104:153-163. https://doi.org/10.1029/1998JA900068

1108 Tenfjord P, Hesse M, Norgren C, Spinnangr SF, Kolstø H (2019) The impact of oxygen

1109 on the reconnection rate. Geophys Res Lett 46:6195-6203. https://doi.org/10.1029/2019GL082175

1111 Tung YK, Carlson CW, McFadden JP, Klumpar DM, Parks GK, Peria WJ, Liou K (2001)

1112 Auroral polar cap boundary ion conic outflow observed on FAST. J Geophys Res 
1114 Valek PW, Delmonico E, McComas DJ, Goldstein J, Allegrini F, Livi S (2018)

1115 Composition of 1-128 keV magnetospheric ENAs. J Geophys Res Space Phys

$1116 \quad$ 123:2668-2678. https://doi.org/10.1002/2017JA024997

1117 Varney RH, Wiltberger M, Lotko W (2015) Modeling the interaction between convection

1118 and nonthermal ion outflows. J Geophys Res Space Phys 120:2353-2362.

1119 https://doi.org/10.1002/2014JA020769

1120 Varney R, Wiltberger M, Zhang B, Lotko W, Lyon J (2016) Influence of ion outflow in

1121 coupled geospace simulations: 2. Sawtooth oscillations driven by physics-based ion

1122 outflow. J Geophys Res Space Phys 121:9688-9700.

$1123 \quad$ https://doi.org/10.1002/2016JA022778

1124 Welling DT, Jordanova VK, Zaharia SG, Glocer A, Toth G (2011) The effects of dynamic

1125 ionospheric outflow on the ring current. J Geophys Res 116:A00J19.

1126 https://doi.org/10.1029/2010JA015642

1127 Welling DT, Jordanova VK, Glocer A, Toth G, Liemohn MW, Weimer DR (2015) The

1128 two-way relationship between ionospheric outflow and the ring current. J Geophys

1129 Res Space Phys 120:4338-4353. https://doi.org/10.1002/2015JA021231 
1130 Welling DT, André M, Dandouras I, Delcourt D, Fazakerley A, Fontaine D, Foster J, Ilie

1131 R, Kistler L, Lee JH, Liemohn MW, Slavin JA, Wang CP, Wiltberger M, Yau A (2016)

1132 The Earth: Plasma sources, losses, and transport processes. In Nagy A, Blanc M,

1133 Chappell C, Krupp N (eds) Plasma Sources of Solar System Magnetospheres. Space

1134 Sciences Series of ISSI, vol 52, Springer, New York, pp. 145-208.

1135 https://doi.org/10.1007/978-1-4939-3544-4_5

1136 Welling DT, Barakat AR, Eccles JV, Schunk RW, Chappell CR (2016) Coupling the

1137 Generalized Polar Wind Model to Global Magnetohydrodynamics. In Chappell CR,

1138 Schunk RW, Banks PM, Burch JL, Thorne RM (eds) Magnetosphere-Ionosphere

1139 Coupling in the Solar System. Geophysical Monograph Series, vol 222, AGU,

1140 Washington, D. C., pp. 179-194. https://doi.org/10.1002/9781119066880.ch14

1141 Wilson GR, Ober DM, Germany GA, Lund EJ (2004) Nightside auroral zone and polar

1142 cap ion outflow as a function of substorm size and phase. J Geophys Res 109:A02206.

1143 https://doi.org/10.1029/2003JA009835

1144 Wiltberger M, Lotko W, Lyon JG, Daminao P, Merkin V (2010) Influence of cusp O

1145 outflow on magnetotail dynamics in a multifluid MHD model of the magnetosphere. 
1147 Yamauchi M (2019) Terrestrial ion escape and relevant circulation in space. Ann Geophys 37(6):1197-1222. https://doi.org/10.5194/angeo-37-1197-2019

1149 Yao Y, Seki K, Miyoshi Y, McFadden JP, Lund EJ, Carlson CW (2008a) Effect of solar

1150 wind variation on low-energy $\mathrm{O}^{+}$populations in the magnetosphere during

1151 geomagnetic storms: FAST observations. J Geophys Res 113:A04220.

$1152 \quad$ https://doi.org/10.1029/2007JA012681

1153 Yao Y, Seki K, Miyoshi Y, McFadden JP, Lund EJ, Carlson CW (2008b) Statistical

1154 properties of the multiple ion band structures observed by the FAST satellite. J

1155 Geophys Res 113:A07204. https://doi.org/10.1029/2008JA013178

1156 Yau AW, Beckwith PH, Peterson WK, Shelley EG (1985) Long-term (solar cycle) and

1157 seasonal variations of upflowing ionospheric ion events at DE 1 altitudes. J Geophys

1158 Res 90:6395-6407. https://doi.org/10.1029/JA090iA07p06395

1159 Yau AW, Abe T, Peterson WK (2007) The polar wind: recent observations. J Atmos Solar

1160 Terr Phys 69(16):1936-1983. https://doi.org/10.1016/j.jastp.2007.08.010

$1161 \mathrm{Yu}$ Y, Ridley AJ (2013) Exploring the influence of ionospheric $\mathrm{O}^{+}$outflow on 
1164 Zeng C, Wang C, Duan S, Dai L, Fuselier SA, Burch JL, Torbert RB, Giles BL (2020)

1165 Statistical study of oxygen ions abundance and spatial distribution in the dayside

1166 magnetopause boundary layer: MMS observations. J Geophys Res Space Phys

1167 125:e2019JA027323. https://doi.org/10.1029/2019JA027323

1168 Zhang SR, Holt JM, van Eyken AP, Heinselman C, McCready M (2010) IPY

1169 observations of ionospheric yearly variations from high- to middle-latitude incoherent

1170 scatter radars. J Geophys Res 115:A03303. https://doi.org/10.1029/2009JA014327

1171 Zhang B, Brambles OJ, Lotko W, Lyon JG (2020) Is nightside outflow required to induce

1172 magnetospheric sawtooth oscillations. Geophys Res Lett 47:e2019GL086419.

$1173 \quad$ https://doi.org/10.1029/2019GL086419

1174 Zheng Y, Moore TE, Mozer FS, Russell CT, Strangeway RJ (2005) Polar study of

1175 ionospheric ion outflow versus energy input. J Geophys Res 110:A07210.

1176 https://doi.org/10.1029/2004JA010995

1177 Zhao K, Kistler LM, Lund EJ, Nowrouzi N, Kitamura N, Strangeway, RJ (2020) Factors 
controlling $\mathrm{O}^{+}$and $\mathrm{H}^{+}$outflow in the cusp during a geomagnetic storm: FAST/TEAMS observations. Geophys Res Lett 46:e2020GL086975. https://doi.org/10.1029/2020GL086975

1181 Zong QG, Fritz TA, Spence HE, Oksavik K, Pu ZY, Korth A, Daly PW (2004) Energetic

1182 particle sounding of the magnetopause: A contribution by Cluster/RAPID. J Geophys Res 109:A04207. https://doi.org/10.1029/2003JA009929

1185 Figure legends

1186 Figure 1. Example of observations at high latitudes. Omnidirectional energy-time

1187 spectrograms of differential energy flux of $\mathbf{a}$ electrons and $\mathbf{b}$ ions, and $\mathbf{c}$ number fluxes

1188 of ions observed by IESA. Blue, black, red, and green bars indicate the periods of the

1189 outflow regions, the subauroral zones, the double loss cones, and the polar cap,

1190 respectively.

1192 Figure 2. SZA distributions of averaged ion number flux in each event. Events at a all

1193 MLT, b only around noon (0800-1600 MLT), and $\mathbf{c}$ only around midnight (2200-2400 
1194 or 0000-0400 MLT). Different symbols and colors indicate different levels of the $K p$

1195 index

1196

1197 Figure 3. Relations between the electron density in the loss cone $(<50 \mathrm{eV})$ and the

1198 mapped outflowing ion number flux in the SZA ranges of $\mathbf{a} 45^{\circ}-85^{\circ}, \mathbf{b} 65^{\circ}-105^{\circ}, \mathbf{c}$

$119985^{\circ}-125^{\circ}$, and $\mathbf{d} 105^{\circ}-145^{\circ}$, and $\mathbf{f}$ comparisons among the derived empirical relations in

1200 these SZA ranges and the empirical formula derived by Strangeway et al. (2005) (their

1201 Equation 4) (multiplied by a factor of 2.9 to correct for the altitudinal difference of the

1202 ion number flux) (dotted gray line). Weighted averages and standard deviations are

1203 plotted as red crosses and solid lines. Dotted red lines indicate the empirical relations

1204 derived by the fitting. In Figure 3e, the empirical relations in the SZA ranges of $45^{\circ}-$

$120585^{\circ}, 65^{\circ}-105^{\circ}, 85^{\circ}-125^{\circ}$, and $105^{\circ}-145^{\circ}$ are shown using red-dashed, orange dashed-

1206 dotted-dotted, green dashed-doted, and blue solid lines, respectively.

1207

1208 Figure 4. Relations between the precipitating electron density $(<50 \mathrm{eV})$ and the

1209 mapped outflowing ion number flux in the SZA ranges of $\mathbf{a} 45^{\circ}-85^{\circ}, \mathbf{b} 65^{\circ}-105^{\circ}, \mathbf{c}$ 
$121085^{\circ}-125^{\circ}$, and $\mathbf{d} 105^{\circ}-145^{\circ}$, and $\mathbf{e}$ comparisons among the derived empirical relations

1211 in these SZA ranges and the empirical formula derived by Strangeway et al. (2005)

1212 (their Equation 3) (multiplied by a factor of 2.9 to correct for the altitudinal difference

1213 of the ion number flux and the precipitating electron density) (dotted gray line). The

1214 format is identical to that of Figure 3. There are three data points below precipitating

1215 electron density of $3 \times 10^{-3} \mathrm{~cm}^{-3}$.

1216

1217 Figure 5. Relations between the mapped DC Poynting flux $(<0.125 \mathrm{~Hz})$ and the

1218 mapped outflowing ion number flux in the SZA ranges of $\mathbf{a} 45^{\circ}-85^{\circ}, \mathbf{b} 65^{\circ}-105^{\circ}, \mathbf{c}$

$121985^{\circ}-125^{\circ}, \mathbf{d} 105^{\circ}-145^{\circ}$, and $\mathbf{e} 45^{\circ}-145^{\circ}$ (all events), and f comparisons among the

1220 derived empirical relations in these SZA ranges and the empirical formula derived by

1221 Strangeway et al. (2005) (their Equation 5) (multiplied by a factor of 2.9 to correct for

1222 the altitudinal difference of the ion number flux and the DC Poynting flux) (dotted gray

1223 line). The format of Figure $5 \mathrm{a}-5 \mathrm{e}$ is identical to that of Figure $3 \mathrm{a}-3 \mathrm{~d}$. In Figure $5 \mathrm{f}$, the

1224 empirical relations in the SZA ranges of $45^{\circ}-145^{\circ}$ (all data) are shown using a thick

1225 black line, in addition to the format of Figure 3e. 
1227 Figure 6. Relations between the mapped Alfvén Poynting flux $(0.125-0.5 \mathrm{~Hz})$ and the

1228 mapped outflowing ion number flux in the SZA ranges of $\mathbf{a} 45^{\circ}-85^{\circ}, \mathbf{b} 65^{\circ}-105^{\circ}, \mathbf{c}$

$122985^{\circ}-125^{\circ}, \mathbf{d} 105^{\circ}-145^{\circ}$, and $\mathbf{e} 45^{\circ}-145^{\circ}$ (all events), and f comparisons among the

1230 derived empirical relations in the SZA ranges and the empirical formula derived by

1231 Brambles et al. (2011) (multiplied by a factor of 2.9 here to correct for the altitudinal

1232 difference of the ion number flux and the Alfvén Poynting flux) (dotted gray line). The

1233 format is identical to that of Figure 5.

1234 


\section{Figures}

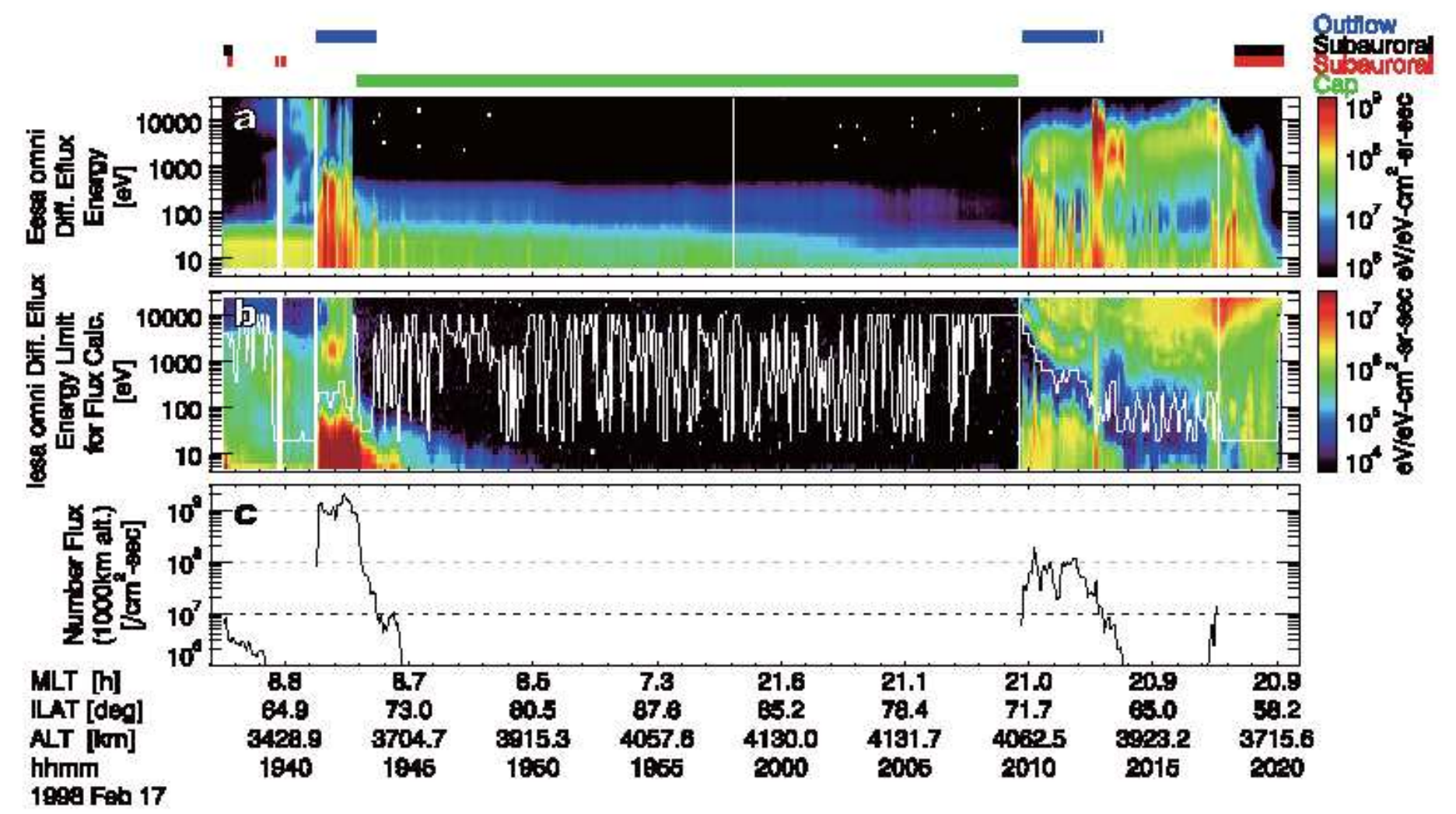

Figure 1

Example of observations at high latitudes. Omnidirectional energy-time spectrograms of differential energy flux of a electrons and $b$ ions, and $c$ number fluxes of ions observed by IESA. Blue, black, red, and green bars indicate the periods of the outflow regions, the subauroral zones, the double loss cones, and the polar cap, respectively. 



Figure 2

SZA distributions of averaged ion number flux in each event. Events at a all MLT, b only around noon (0800-1600 MLT), and c only around midnight (2200-2400 or 0000-0400 MLT). Different symbols and colors indicate different levels of the Kp index. 

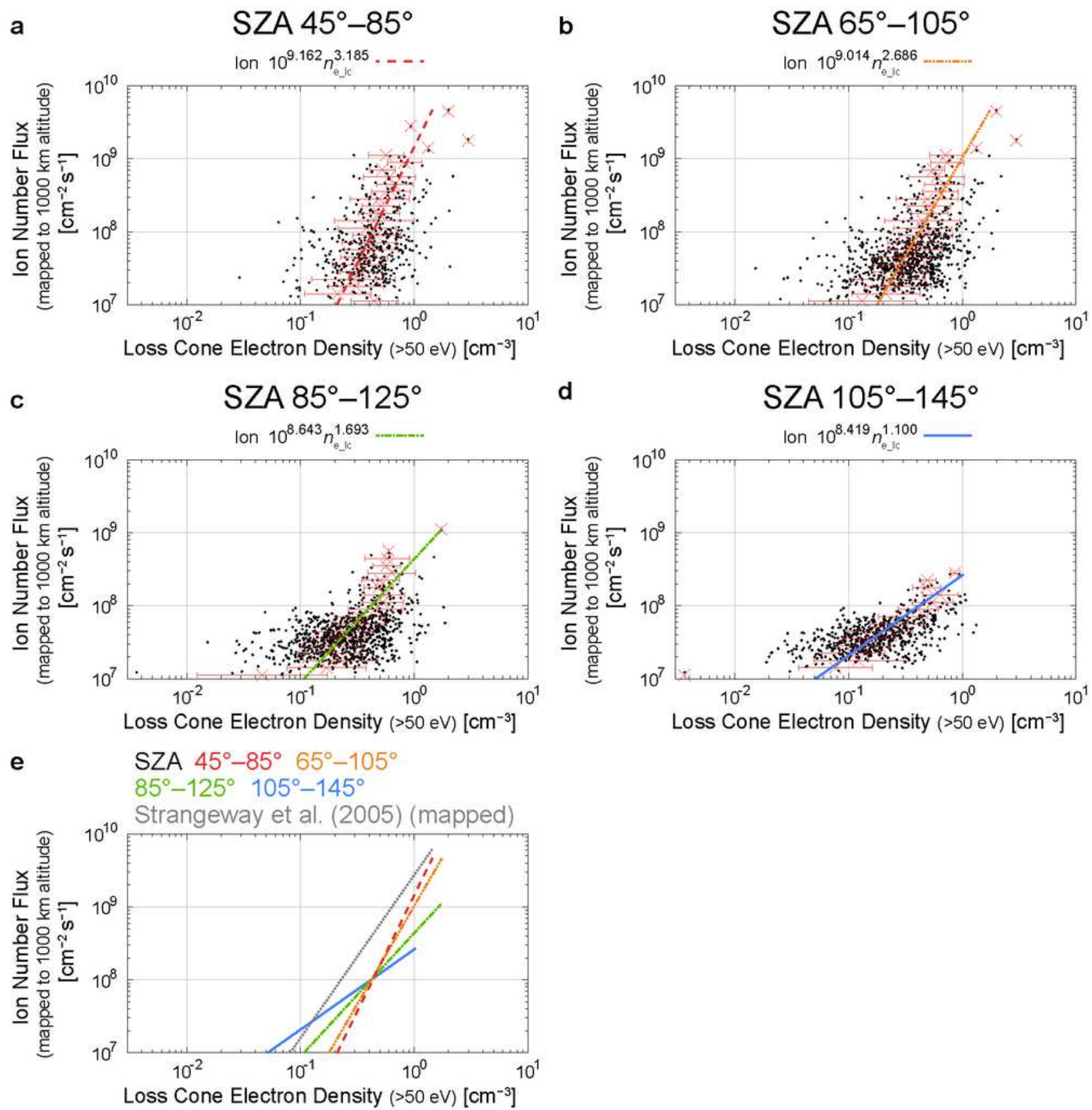

\section{Figure 3}

Relations between the electron density in the loss cone $(<50 \mathrm{eV})$ and the mapped outflowing ion number flux in the SZA ranges of a $45^{\circ}-85^{\circ}, \mathrm{b} 65^{\circ}-105^{\circ}, \mathrm{c} 85^{\circ}-125^{\circ}$, and $\mathrm{d} 105^{\circ}-145^{\circ}$, and $\mathrm{f}$ comparisons among the derived empirical relations in these SZA ranges and the empirical formula derived by Strangeway et al. (2005) (their Equation 4) (multiplied by a factor of 2.9 to correct for the altitudinal difference of the ion number flux) (dotted gray line). Weighted averages and standard deviations are 
plotted as red crosses and solid lines. Dotted red lines indicate the empirical relations derived by the fitting. In Figure $3 e$, the empirical relations in the SZA ranges of $45^{\circ}-85^{\circ}, 65^{\circ}-105^{\circ}, 85^{\circ}-125^{\circ}$, and $105^{\circ}-$ $145^{\circ}$ are shown using red-dashed, orange dashed-dotted-dotted, green dashed-doted, and blue solid lines, respectively.
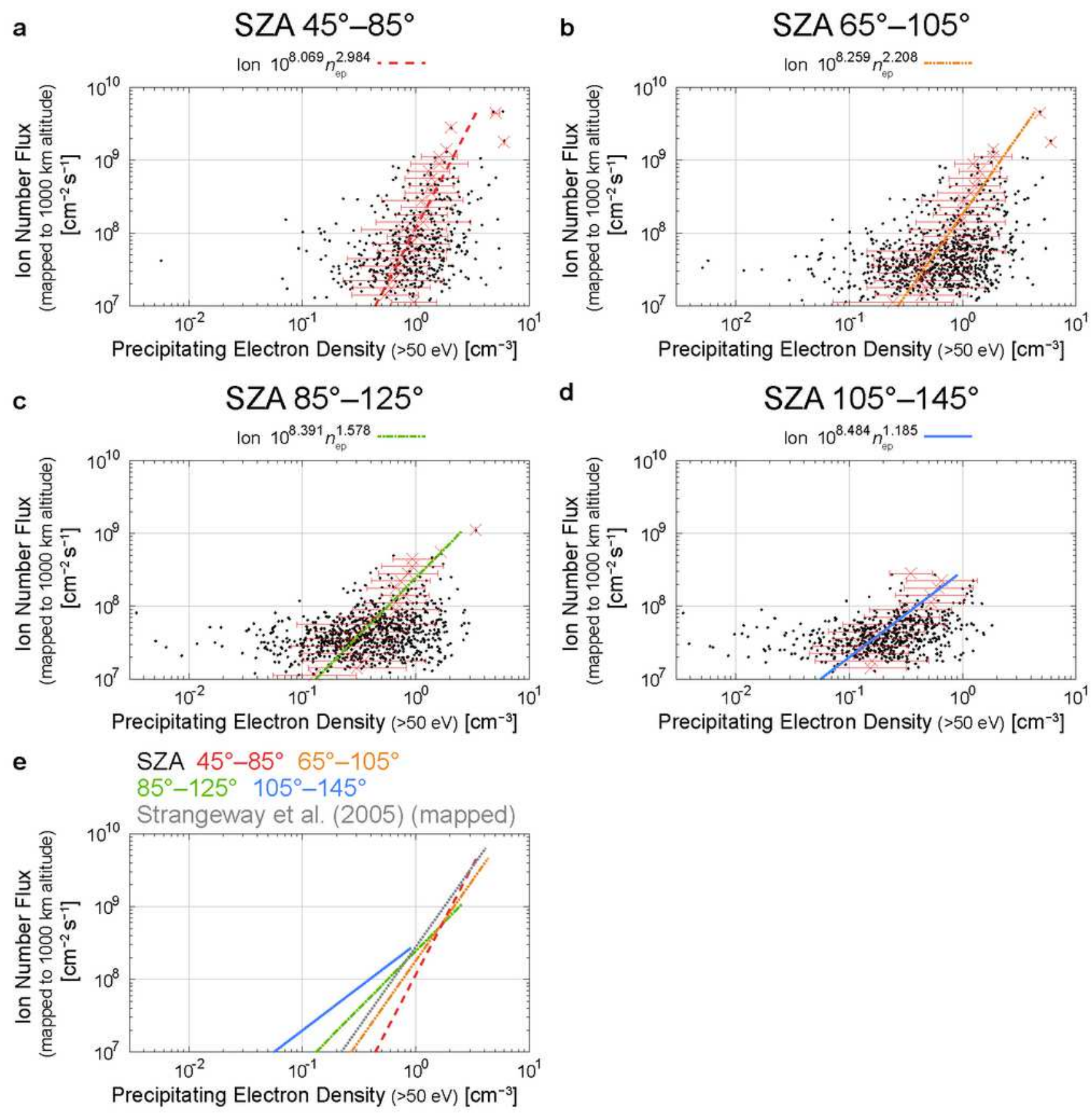

\section{Figure 4}


Relations between the precipitating electron density $(<50 \mathrm{eV})$ and the mapped outflowing ion number flux in the SZA ranges of a $45^{\circ}-85^{\circ}, \mathrm{b} 65^{\circ}-105^{\circ}, \mathrm{c} 85^{\circ}-125^{\circ}$, and $\mathrm{d} 105^{\circ}-145^{\circ}$, and e comparisons among the derived empirical relations in these SZA ranges and the empirical formula derived by Strangeway et al. (2005) (their Equation 3) (multiplied by a factor of 2.9 to correct for the altitudinal difference of the ion number flux and the precipitating electron density) (dotted gray line). The format is identical to that of Figure 3 . There are three data points below precipitating electron density of $3 \times 10-3 \mathrm{~cm}-3$.
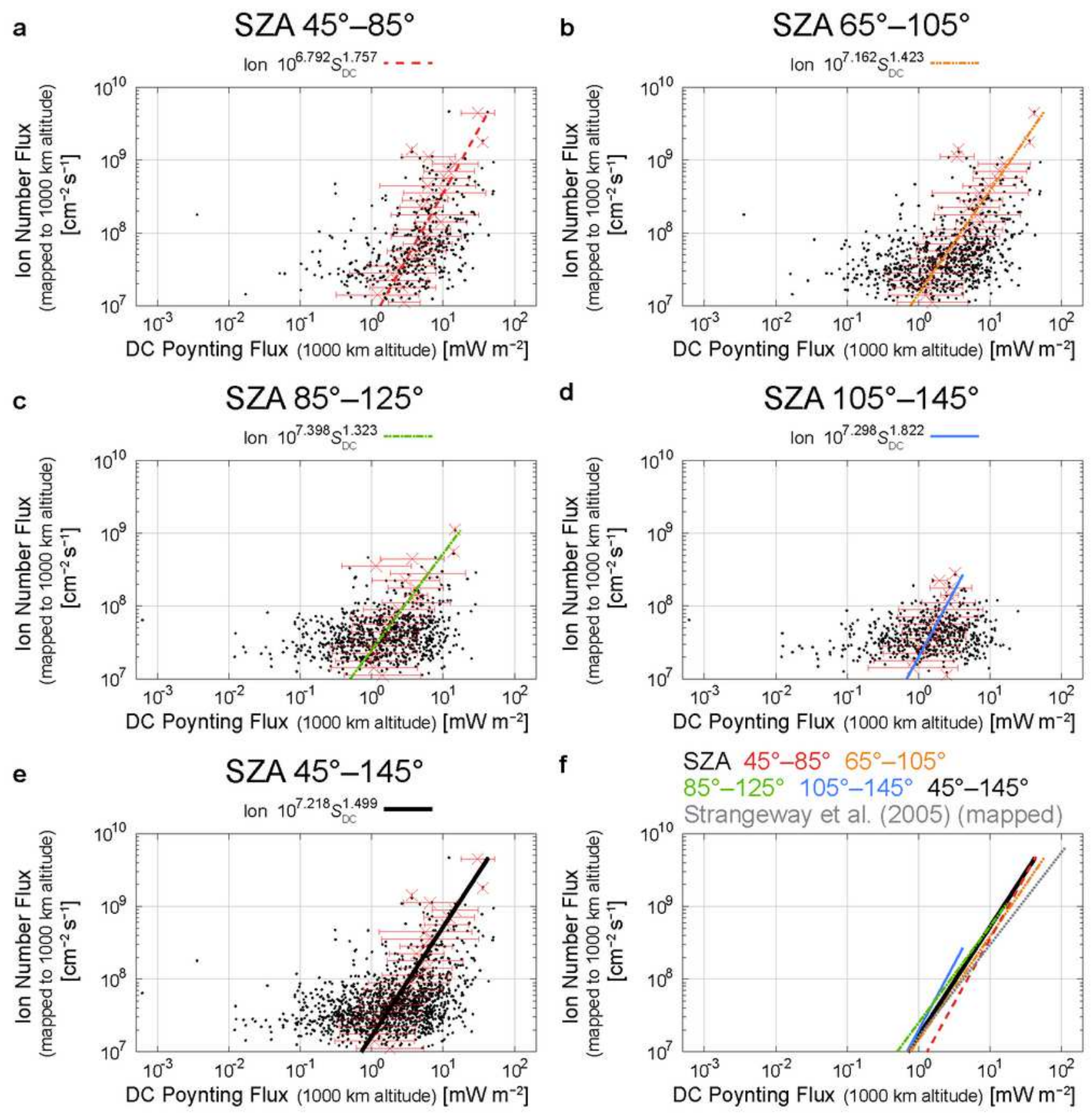
Relations between the mapped DC Poynting flux $(<0.125 \mathrm{~Hz})$ and the mapped outflowing ion number flux in the SZA ranges of a $45^{\circ}-85^{\circ}, \mathrm{b} 65^{\circ}-105^{\circ}, \mathrm{c} 85^{\circ}-125^{\circ}, \mathrm{d} 105^{\circ}-145^{\circ}$, and e $45^{\circ}-145^{\circ}$ (all events), and $\mathrm{f}$ comparisons among the derived empirical relations in these SZA ranges and the empirical formula derived by Strangeway et al. (2005) (their Equation 5) (multiplied by a factor of 2.9 to correct for the altitudinal difference of the ion number flux and the DC Poynting flux) (dotted gray line). The format of Figure $5 a-5 e$ is identical to that of Figure $3 a-3 d$. In Figure $5 f$, the empirical relations in the SZA ranges of $45^{\circ}-145^{\circ}$ (all data) are shown using a thick black line, in addition to the format of Figure $3 \mathrm{e}$.
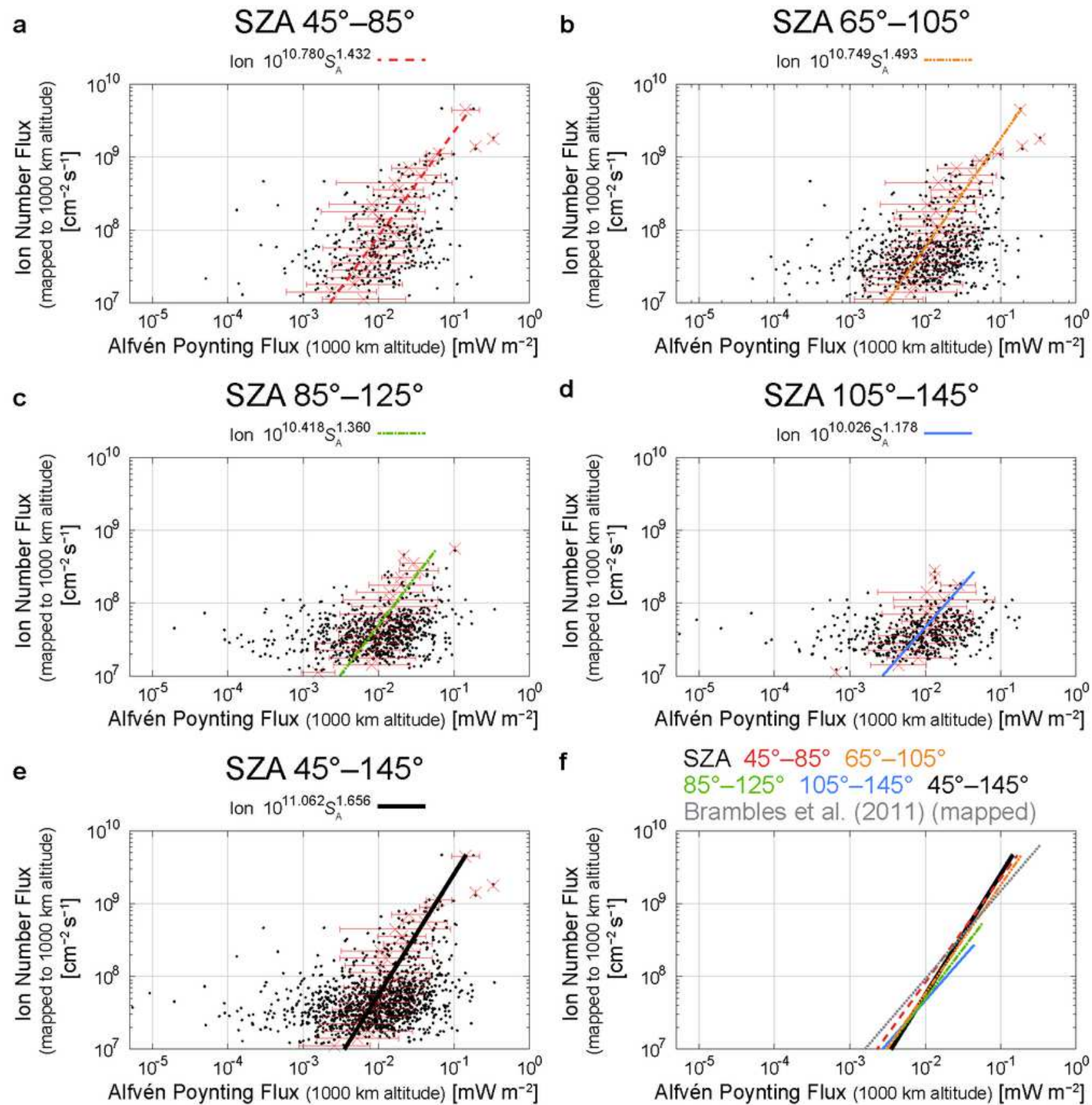

Alfvén Poynting Flux (1000 km altitude) $\left[\mathrm{mW} \mathrm{m}^{-2}\right]$

Alfvén Poynting Flux (1000 km altitude) [ $\mathrm{mW} \mathrm{m}^{-2}$ ] 
Figure 6

Relations between the mapped Alfvén Poynting flux $(0.125-0.5 \mathrm{~Hz})$ and the mapped outflowing ion number flux in the SZA ranges of a $45^{\circ}-85^{\circ}, \mathrm{b} 65^{\circ}-105^{\circ}, \mathrm{c} 85^{\circ}-125^{\circ}, \mathrm{d} 105^{\circ}-145^{\circ}$, and e $45^{\circ}-145^{\circ}$ (all events), and $f$ comparisons among the derived empirical relations in the SZA ranges and the empirical formula derived by Brambles et al. (2011) (multiplied by a factor of 2.9 here to correct for the altitudinal difference of the ion number flux and the Alfvén Poynting flux) (dotted gray line). The format is identical to that of Figure 5.

\section{Supplementary Files}

This is a list of supplementary files associated with this preprint. Click to download.

- GraphicalAbstract.png 